\title{
Comparison of Analysis and Spectral Nudging Techniques for Dynamical Downscaling with the WRF Model over China
}

\author{
Yuanyuan Ma, Yi Yang, Xiaoping Mai, Chongjian Qiu, Xiao Long, and Chenghai Wang
}

Key Laboratory of Arid Climatic Changing and Reducing Disaster of Gansu Province, College of Atmospheric Sciences, Lanzhou University, Lanzhou 730000, China

Correspondence should be addressed to Yi Yang; yangyi@lzu.edu.cn

Received 19 May 2016; Revised 20 October 2016; Accepted 17 November 2016

Academic Editor: Roberto Fraile

Copyright (C) 2016 Yuanyuan Ma et al. This is an open access article distributed under the Creative Commons Attribution License, which permits unrestricted use, distribution, and reproduction in any medium, provided the original work is properly cited.

To overcome the problem that the horizontal resolution of global climate models may be too low to resolve features which are important at the regional or local scales, dynamical downscaling has been extensively used. However, dynamical downscaling results generally drift away from large-scale driving fields. The nudging technique can be used to balance the performance of dynamical downscaling at large and small scales, but the performances of the two nudging techniques (analysis nudging and spectral nudging) are debated. Moreover, dynamical downscaling is now performed at the convection-permitting scale to reduce the parameterization uncertainty and obtain the finer resolution. To compare the performances of the two nudging techniques in this study, three sensitivity experiments (with no nudging, analysis nudging, and spectral nudging) covering a period of two months with a grid spacing of $6 \mathrm{~km}$ over continental China are conducted to downscale the 1-degree National Centers for Environmental Prediction (NCEP) dataset with the Weather Research and Forecasting (WRF) model. Compared with observations, the results show that both of the nudging experiments decrease the bias of conventional meteorological elements near the surface and at different heights during the process of dynamical downscaling. However, spectral nudging outperforms analysis nudging for predicting precipitation, and analysis nudging outperforms spectral nudging for the simulation of air humidity and wind speed.

\section{Introduction}

General circulation models (GCMs) are primary tools for studying the Earth's climate system and understanding climate changes in the future and responses to climate changes with emissions in terms of the simulation of different climate system components, averages, variability, and extremes. Moreover, regional-scale climate information can be extracted from coupled atmosphere-ocean general circulation models (AOGCMs) [1]. However, the horizontal resolution of GCMs or AOGCMs may be too low to identify features that are important at the regional or local scales [14]. To overcome this problem, downscaling of the GCM and AOGCM results or reanalysis over a limited-area domain can be used to generate region-specific climate information.

Dynamical downscaling, which is an extremely important and broadly used method, is based on the physical and dynamical framework of regional climate models
(RCMs) and became a common approach for obtaining highresolution regional climate information. It is forced by largescale circulation of the GCM results or global reanalysis and adds regional detailed representation of local processes, topography, land cover, and other features that shape the regional climate [5-7]. Dynamical downscaling ability may be affected by many factors, which can be classified into two types. The first type of factor comes from the limitations in the physical representations in RMCs, including cloud-related processes and land-surface/atmosphere interactions, cumulus convection schemes [8], the combination of schemes for convection and the planetary boundary layer, horizontal diffusion, and/or microphysics [9-14]. The other type of factor comes from the choice and application of the boundary conditions (driving data) and domains [1], which are rooted in dynamical downscaling itself. The starting point of dynamical downscaling is typically a set of coarse-resolution largescale fields that are used to provide the initial conditions (ICs) 
and lateral boundary conditions (LBCs) for the RCMs [15]. Thus, which are the best ICs and LBCs $[16,17]$, how to reduce RCMs' internal variability [18-21], the impact of different driving data or strategies to inhibit the growth of errors [22$25]$, and the influence of domain size, domain position, and resolution [20,22, 26-28] on dynamical downscaling are the primary issues in related studies.

Among the factors which cause errors and uncertainties in the dynamical downscaling process, we focus on a strategy that balances the performance of RCMs in adding small-scale features while retaining large-scale features. This strategy is called nudging, which provides a method for constraining the RCMs and keeps them from diverging too far from the coarse-scale fields.

RCMs are strongly constrained by the driving data near the lateral boundaries. Thus, in small domains, RCMs have less freedom to generate additional information. Moreover, larger domains allow the RCM solutions to become increasingly "decoupled" from the driving data [1], which is one key source of systematic errors in dynamical downscaling [29]. Nudging techniques (methods for adding a correction to the predictive equation of the variable to be adjusted at the grid point in the model) have proved to be useful for preventing RCMs from drifting away from large-scale driving fields $[1,15,30-32]$.

The nudging used in dynamical downscaling is currently applied in two different ways: analysis nudging [33] and spectral nudging [34]. Analysis nudging is conducted in every grid cell, while spectral nudging is applied in zonal and meridional directions, and only the waves under the selected wave numbers are retained in the nudging term $[29,31$, $32,34-36]$. Studies have used analysis nudging and spectral nudging in dynamical downscaling to obtain more accurate regional climate information $[15,30,31,37-39]$. However, the performances of the two nudging techniques are debated. On the one hand, analysis nudging is generally superior to spectral nudging when appropriate nudging coefficients are chosen to adjust the strength of the nudging force in the governing equations [38]. The precipitation intensity and frequencies predicted by analysis nudging are closer to the observed values than those predicted by spectral nudging [40]. On the other hand, using spectral nudging has advantages over using no nudging or using boundary nudging [41-44] and could theoretically outperform analysis nudging, which risks overforcing the RCMs at small scales [45]. Liu et al. [29] used the Weather Research and Forecasting (WRF) model to compare the performance of analysis nudging and spectral nudging in downscaling and showed that spectral nudging outperformed analysis nudging in balancing the performance of the simulation at large and small scales. For precipitation, Miguez-Macho et al. [35] showed that spectral nudging successfully eliminated the spatial pattern distortions of precipitation when the position of the simulation domain was shifted by $7^{\circ}-17^{\circ} \mathrm{N}$. However, Bullock Jr. et al. [46] indicated that stronger analysis nudging could reduce the positive bias in precipitation and that stronger spectral nudging did not have much effect. Therefore, additional studies comparing analysis nudging and spectral nudging, especially in different regions, are needed.
Since much of the motivation for dynamical downscaling is to capture more detailed representations of local processes, topography, and other features that shape regional climate, higher resolution may be better [12, 47-50]. In addition, very fine resolution datasets are useful for hydrological and other applications [51]. For example, Gutowski Jr. et al. [52] concluded that RCMs could provide better precipitation extremes than GCMs, and Vautard et al. [49] found that, for most regional climate models, warm extremes were generally better simulated in Europe at a resolution of $12 \mathrm{~km}$ runs than at a resolution of $50 \mathrm{~km}$ runs. Rojas [53] and Walther et al. [50] tested the relationships between improved simulation quality and increasing resolution in RCMs and showed that better simulation performance corresponded with higher resolution.

Moreover, dynamical downscaling is now being run at convection-permitting scales, where cumulus parameterization can be replaced by explicit dynamics to represent deep convective systems that will reduce some uncertainties of the parameterization. Thus, one of the future research prospects for dynamical downscaling is to meet high-resolution needs [51]. However, long runs with RCMs at resolution higher than approximately $10 \mathrm{~km}$ remain rare [54], and even fewer RCMs run at convection-permitting resolutions [1]. Guttler et al. [47] noted that a $6 \mathrm{~km}$ run would provide more improvement in some researched regions, and Pryor et al. [48] found that the impacts of higher RCMs resolution ( $6 \mathrm{~km}$ compared with $50 \mathrm{~km}$ ) were much larger when extreme wind speeds occurred relative to the mean wind speed. Considering resolution needs and the computational expense, we conducted this study using a resolution of $6 \mathrm{~km}$.

In this study, three sensitivity experiments (with no nudging, analysis nudging, and spectral nudging) with a grid spacing of $6 \mathrm{~km}$ over continental China are conducted to investigate the performance of two nudging techniques when downscaling the 1-degree NCEP dataset using the WRF model.

Details regarding the model and experimental setup are described in Section 2. In Section 3, the evaluation datasets are introduced and the evaluation methods are presented. The verification and comparison of simulate performance with different nudging techniques are presented in Section 4. Finally, the conclusions are presented in Section 5.

\section{Model Description and Experimental Setup}

2.1. Model Description. The regional climate model used in this study is the WRF model, version 3.5.1, with the Advanced Research WRF dynamic core. The initial and boundary conditions for the large-scale atmospheric fields, as well as the initial soil parameters (soil water, moisture, and temperature), are obtained from $1^{\circ} \times 1^{\circ}$ National Centers for Environmental Prediction Final Operational Global Analysis data (FNL). The simulation domain is centered at $35^{\circ} \mathrm{N}$ and $105^{\circ} \mathrm{E}$ with $1009 \times 805$ horizontal grid points and a grid spacing of $6 \mathrm{~km}$ across China (Figure 1). The vertical dimension included 28 terrain-following eta vertical coordinate levels, and the pressure at the top of the model is $10 \mathrm{hPa}$. 


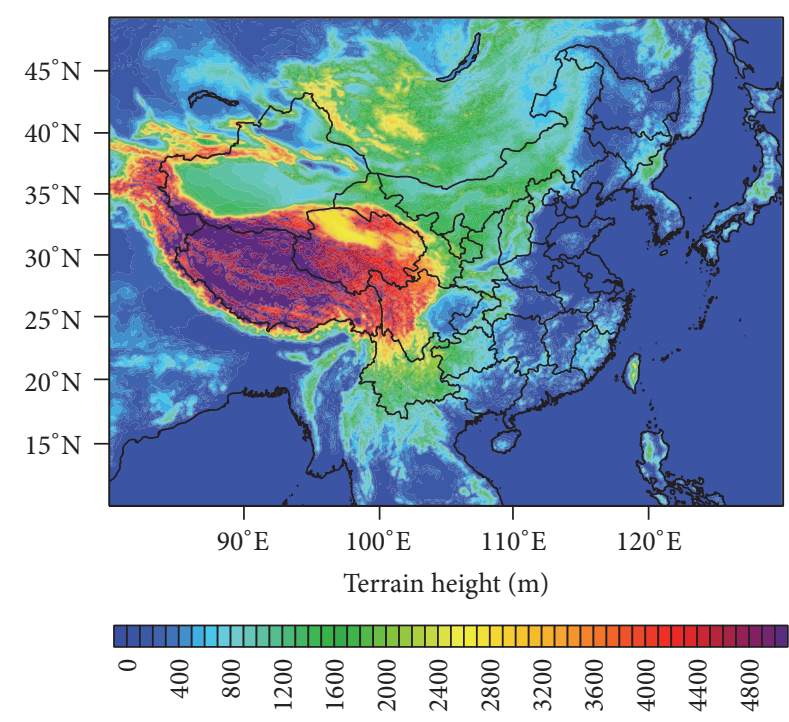

FIGURE 1: WRF model domain and topography height map and the color scale refers to elevation.

The domain-specified lateral boundary was composed of a one-point specified zone and a four-point relaxation zone, with nudging toward the FNL data using the method of Davies and Turner [55] to reduce the generation of noise at the boundaries. In addition, the Lambert conformal conic projection was used.

In this study, the sea surface temperature (SST) is updated every $6 \mathrm{~h}$. The SST data is provided by the National Oceanic and Atmospheric Administration Optimum Interpolation Sea Surface Temperature Analysis, which is on a one-degree grid. This analysis SSTs data is from in situ and satellite and SSTs simulated using sea ice cover and has reduced bias in the SST at higher latitudes. Besides, the deep-layer soil temperature is updated because it is also necessary for long simulations [56].

The main physical options used here include the WRF single-moment six-class (WSM6) microphysical parameterization [57], Rapid Radiative Transfer Model longwave radiation [58], Dudhia shortwave radiation [59], the Yonsei University planetary boundary layer scheme [60], and the Noah land-surface model [61]. This study is conducted at a grid spacing of $6 \mathrm{~km}$ and it is at a convection-permitting scale; thus, no cumulus parameterization is used. The model was integrated from 1200 UTC on April 15th to 1200 UTC on July 1st, 2011. The initial 15 days are considered as a spin-up period, and the outputs during this period are excluded from the analysis, so only the results from 1 May to 30 June are used in the analysis.

2.2. Experimental Setup. In this study, three sensitivity experiments are conducted to investigate the performances of nudging in dynamical downscaling. The first one is continuous integrations with no nudging, and the others are continuous integrations with the two nudging techniques. The two interior nudging options used here are analysis nudging and spectral nudging. The physical configurations in WRF are kept the same for all the three sensitivity experiments, except the nudging technique employed. Analysis nudging is applied to the horizontal wind components, potential temperature, and water vapor mixing ratio. And it is only applied above the PBL. Spectral nudging is applied to the horizontal wind components, potential temperature, and geopotential height above the PBL. Here, the geopotential field is nudged, instead of the water vapor mixing ratio, because it can only be applied to four variables in public releases and currently cannot be applied to the water vapor mixing ratio, for it does not have large-scale features as strong as other fields. The wave number used in the spectral nudging experiment in the zonal and meridional directions is set to constant value 3 . The nudging coefficients for all variables for both analyses and spectral nudging experiments are set at $0.0003 \mathrm{~s}^{-1}$ [29]. The nudging is applied until the end of the simulation.

\section{Evaluation Datasets and Methods}

3.1. Evaluation Datasets. The satellite-derived rainfall from the Monthly Tropical Rainfall Measuring Mission (TRMM) 3B43 dataset, which has a spatial resolution of $0.25^{\circ}$ in the latitude band $50^{\circ} \mathrm{N}-50^{\circ} \mathrm{S}$, is used as a part of this study for precipitation validation. This dataset provides important data that can be used to detect rainfall globally [62], particularly over East Asia [63, 64]. The monthly TRMM 3B43 precipitation and the monthly precipitation obtained from the National Meteorological Information Center (NMIC) of the China Meteorological Administration (http://data.cma.cn/) agreed well over China. Thus, the monthly TRMM $3 \mathrm{~B} 43$ precipitation can be viewed as a reasonable criterion for verifying downscaled results. When only considering precipitation in China, all of the simulated monthly accumulated precipitation data are interpolated into grids with a spatial resolution of $0.25^{\circ}$ (obtained from the NMIC) using bilinear interpolation. Moreover, the precipitation from the real time analysis system with $0.25^{\circ}$ grids and daily precipitation over China (1st edition) obtained from the NMIC (http://data.cma.cn/data/detail/dataCode/ SEVP_CLI_CHN_PRE_DAY_GRID_0.25.html) is also used to validate the simulated daily accumulated precipitation.

The datasets used for comparisons with other variables, such as temperature, relative humidity, wind speed, and pressure near the surface, are obtained from the NMIC, but variables such as the water vapor mixing ratio and the geopotential height at different levels were obtained from the third-generation European Centre for Medium-Range Weather Forecasts reanalysis product INTERIM (ERA-IN) data [65]. In this study, we chose the above two datasets for two reasons. First, the ERA-IN data cannot generate realistic regional structures at the surface for the regional topography and land-surface characteristics but is consistent with the large-scale behavior of the monthly upper air specific layers dataset for China. The correlation coefficients of the two datasets, including temperature, relative humidity, wind speed, and pressure near the surface, and the temperature, wind speed, and geopotential heights at different levels are calculated. These calculations show that the correlation coefficients between the variables near the surface are relatively 
low and that the variables in the upper air are higher. Second, many values are missing from the upper air specific layers data from the NMIC, especially for dew-point, temperature, and the variables at $850 \mathrm{hPa}$ and $700 \mathrm{hPa}$.

To facilitate comparison, all simulated variables, including the simulated daily precipitation and the related ERA-IN variables (given by directly interpolating ERA-IN to the $6-\mathrm{km}$ WRF grid), have been bilinearly interpolated into the Chinese observed stations.

3.2. Evaluation Methods. Evaluation of the three WRF downscaling experiments is performed using a simple space distribution of the variables and some statistical verification techniques over China by comparing the simulated results with the observed data mentioned above. The following statistical verification techniques are calculated, with $M$ representing the model simulation values, $O$ representing the observed values, and $N$ representing the total number of verification points.
The mean error (ME), which indicates whether the simulation over- or underestimates the mean magnitude of the observed values, is defined as follows:

$$
\mathrm{ME}=\frac{1}{N} \sum_{i=1}^{N}\left(M_{i}-O_{i}\right) .
$$

The root mean square error (RMSE), which provides an overview of the accuracy of the simulations and the observations, is defined as follows:

$$
\operatorname{RMSE}=\left[\frac{1}{N} \sum_{i=1}^{N}\left(M_{i}-O_{i}\right)^{2}\right]^{1 / 2} .
$$

The correlation coefficient (cc), which shows the relationship between the simulation and observed values, is defined as follows:

$$
\mathrm{cc}=\frac{(1 /(N-1))\left[\sum_{i=1}^{N}\left[\left(M_{i}-\bar{M}\right)\left(O_{i}-\bar{O}\right)\right]\right]}{\left[(1 /(N-1))\left[\sum_{i=1}^{N}\left(M_{i}-\bar{M}\right)^{2}\right]\right]^{1 / 2}\left[(1 /(N-1))\left[\sum_{i=1}^{N}\left(O_{i}-\bar{O}\right)^{2}\right]\right]^{1 / 2}}
$$

Moreover, four other statistical verification techniques are used to evaluate the accumulated precipitation. First, the bias score (BS) is used to indicate whether the model over- or underestimates the fractional areal coverage of precipitation for a certain threshold, and its optimal value is 1 . Second, the threat score (TS) is used to measure the ability of the model to predict the area of precipitation for a certain threshold [15]; that is, the bigger the better. Third, the rate of missing simulates (PO) is used to indicate the proportion of nonforecasts of precipitation for a certain threshold based on the actual occurrence of the event; that is, the smaller the better. Fourth, NH is used to indicate the proportion of the forecasts of precipitation for a certain threshold of occurrence when the actual event does not occur; that is, the smaller the better.

The BS, TS, PO, and $\mathrm{NH}$ are defined as follows:

$$
\begin{aligned}
\mathrm{BS} & =\frac{M}{O}, \\
\mathrm{TS} & =\frac{H}{M+O-H}, \\
\mathrm{PO} & =\frac{N C}{H+N C}, \\
\mathrm{NH} & =\frac{N B}{H+N B},
\end{aligned}
$$

where $M$ is the number of points at which the threshold amount of precipitation is simulated, $O$ is the number of points that the threshold amount is observed, $H$ is the number of points that threshold precipitation is both simulated and observed, $N C$ is the number of points at which the threshold amount is observed but not simulated, and $N B$ is the number of points at which threshold precipitation is simulated but not observed. The threshold amounts used for monthly accumulated precipitation are $30 \mathrm{~mm}, 50 \mathrm{~mm}$, $60 \mathrm{~mm}, 100 \mathrm{~mm}, 150 \mathrm{~mm}, 200 \mathrm{~mm}, 250 \mathrm{~mm}$, and $300 \mathrm{~mm}$, and the threshold for daily accumulated precipitation is $10 \mathrm{~mm}$.

\section{Results}

4.1. Precipitation Verification. The reproduction of precipitation is critical for regional climate downscaling applications. Figure 2 shows the downscaling skill of the three WRF runs for predicting monthly accumulated precipitation. According to the monthly TRMM 3B43 observational data, precipitation mainly occurs in the East Asia summer monsoon region, and northwestern China is relatively drier. The maximum precipitation occurs in the southern region in May and in the Yangtze River delta region in June.

The three WRF simulations reproduce the precipitation distribution. However, the precipitation simulated by WRF with no nudging is too high throughout southern China and southwestern China in May and is too dry throughout northern China and northeastern China when compared with the TRMM. In June, the simulated precipitation is too high throughout northern China, southern China, and southwestern China and is too dry throughout the Yangtze River delta and in northeastern China. This model overestimates the maximum precipitation and additionally misplaces the locations of the maximum precipitation in June, which are farther south of the Yangtze River delta region. 


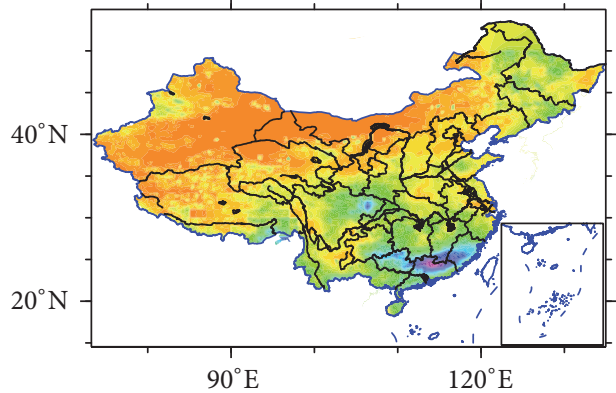

(a) TRMM_May

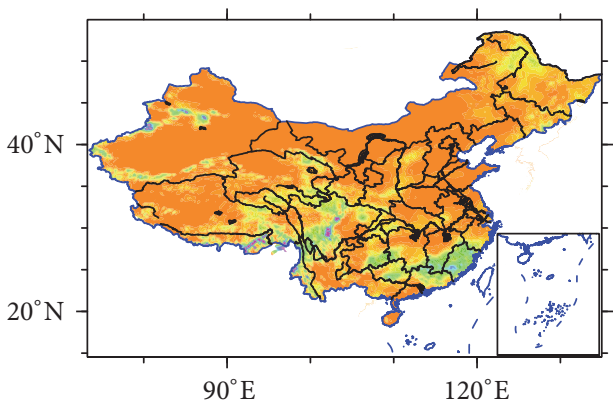

(c) AN_May

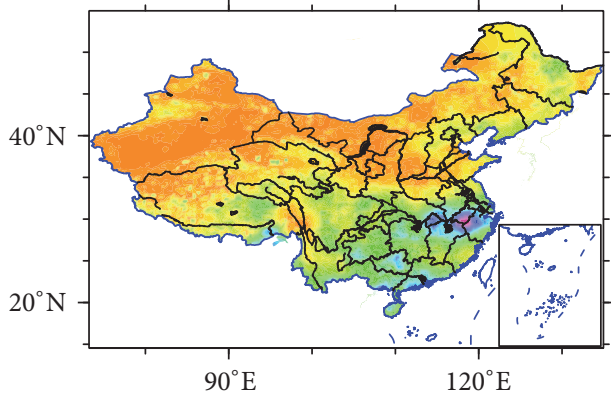

(e) TRMM_June

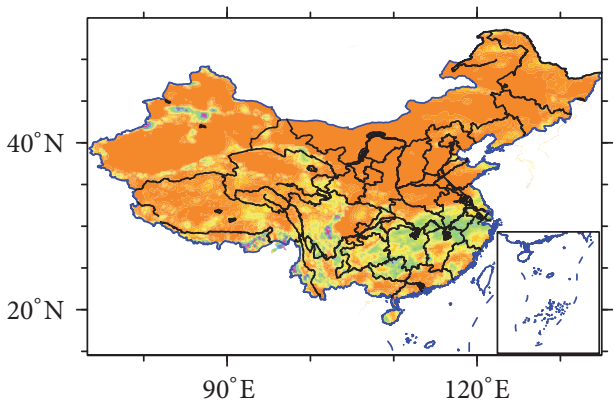

(g) AN_June

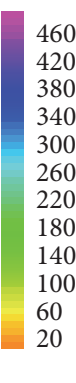

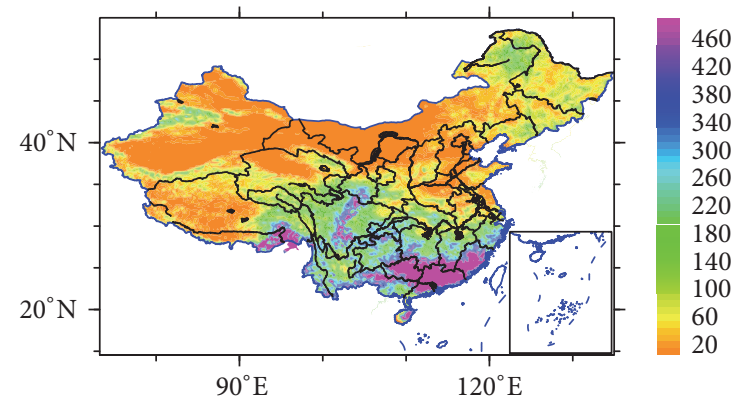

(b) NN_May

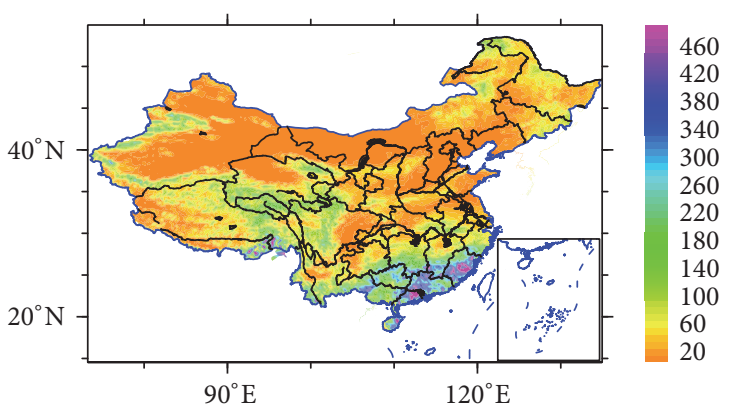

(d) SN_May

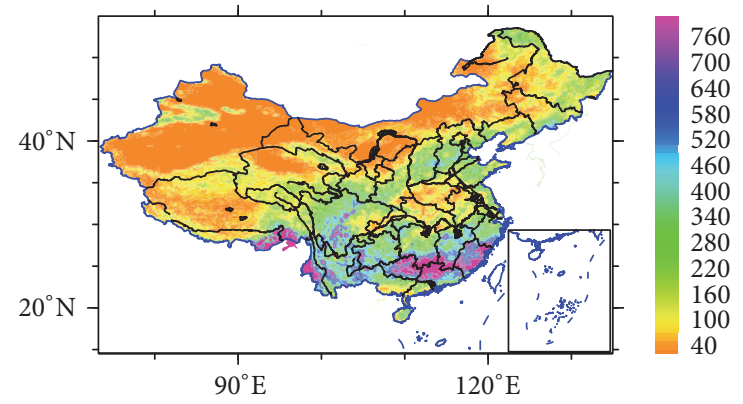

(f) NN_June

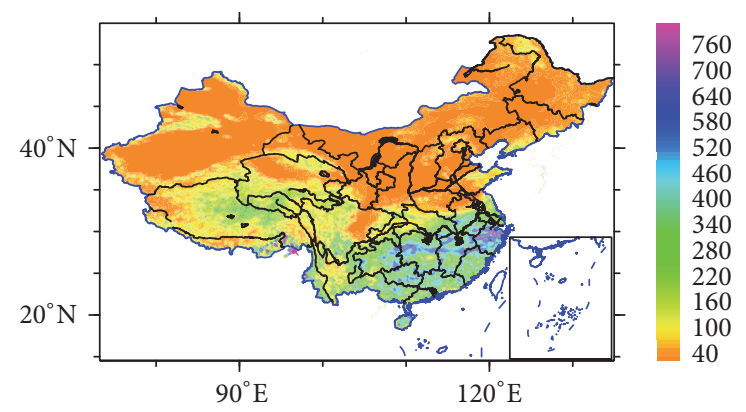

(h) SN_June

FIGURE 2: Comparison of monthly accumulated precipitation (mm) for (a), (e) TRMM observed precipitation (TRMM), (b), (f) WRF simulated precipitation with no nudging $(\mathrm{NN}),(\mathrm{c}),(\mathrm{g})$ WRF simulated precipitation with analysis nudging (AN), and (d), (h) WRF simulated precipitation with spectral nudging (SN) for May 2011 ((a)-(d)) and June $2011((\mathrm{e})-(\mathrm{h}))$.

The nudging experiments generally underpredict the magnitude of precipitation throughout China, and the spectral nudging experiment underestimates the precipitation magnitude in the region north of the Yangtze River. However, the nudging experiments reproduce the maximum precipitation locations, and the spectral nudging experiment reproduces the locations and the maximum precipitation magnitude. The spectral nudging experiment performs better than the analysis nudging experiment; the former indicates a lower bias in the monthly accumulated precipitation simulation regarding the coverage area and magnitude. The spectral nudging experiment performs the best and generally 


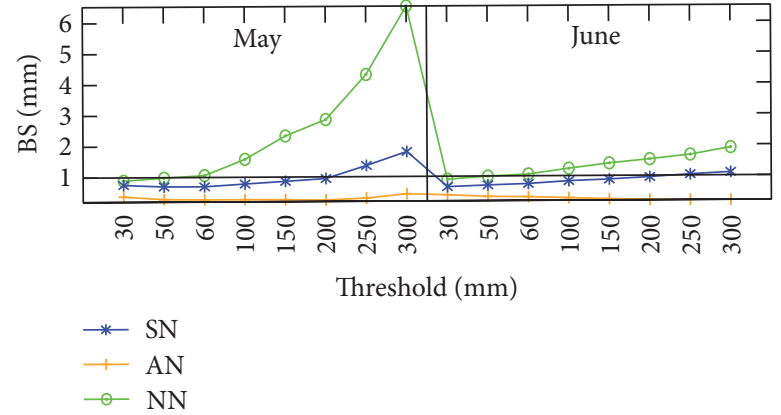

(a)

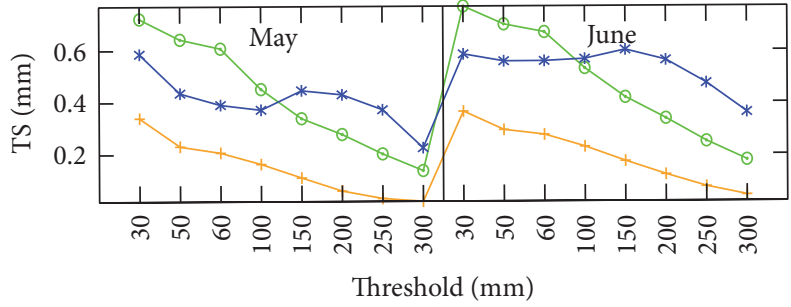

- SN
$-\quad \mathrm{AN}$
$-\mathrm{NN}$

FIgURE 3: The BS and TS at different threshold for monthly accumulated precipitation in May and June, 2011.

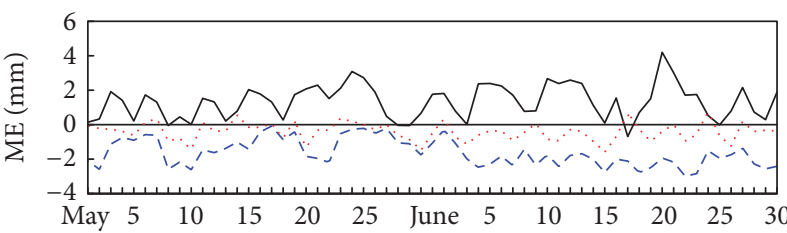

..... $\mathrm{SN}$

... AN

(a)

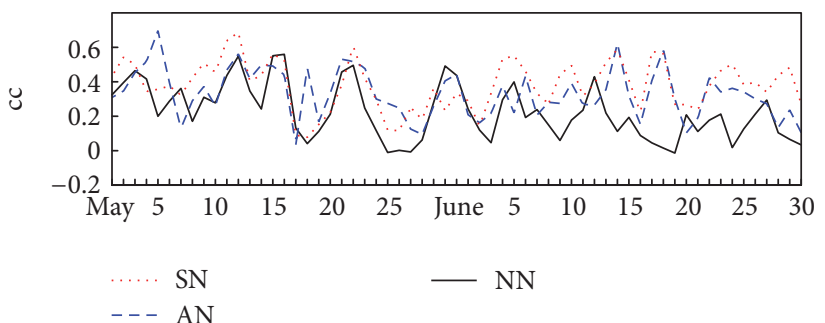

(c)

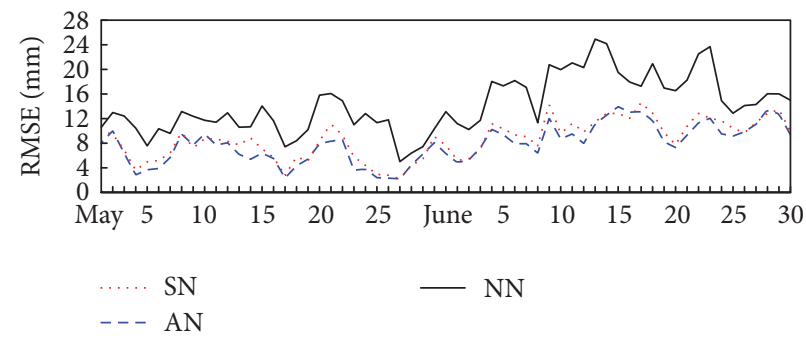

(b)

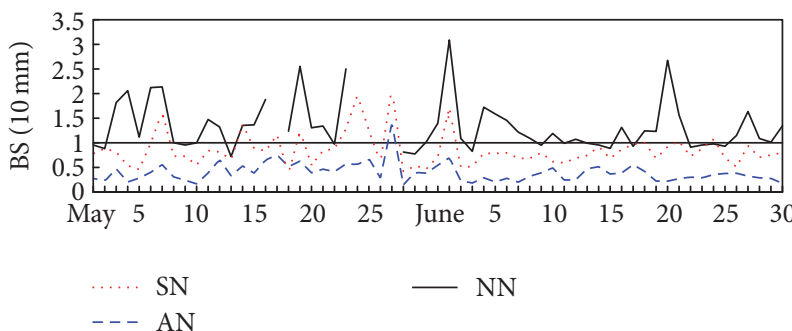

(d)

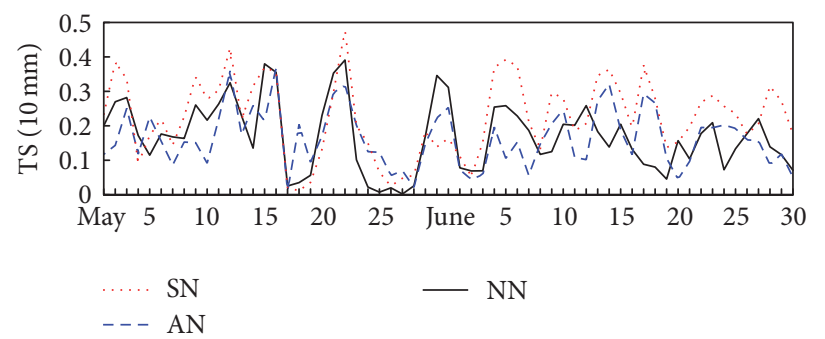

(e)

FIGURE 4: Time series plots of related statistical verification techniques for the daily accumulated precipitation in May and June 2011. (a) The ME between the observations and downscaling results by WRF by NN, AN and SN; (b) the same as (a), but is the RMSE; (c) the same as (a), but is the cc; (d) BS at the threshold of $10 \mathrm{~mm}$ (if the BS value is greater than 3 , we set it as a missing value because it indicates much overprediction of precipitation and makes it difficult to understand the plot); (e) TS at the of 10-threshold mm.

improved the model-simulated areal coverage of precipitation.

The related statistical verification parameters against the TRMM observations are shown in Table 1 and Figures 3 and 4. Overall, the simulations without nudging produce much more precipitation than the observed $(\mathrm{ME}=37.12 \mathrm{~mm}$ and $\mathrm{ME}=43.25 \mathrm{~mm}$ in May and June, resp., perfect $=0$ ).
The analysis nudging experiment underestimates the precipitation $(\mathrm{ME}=-37.30 \mathrm{~mm}$ and $\mathrm{ME}=-62.78 \mathrm{~mm}$ in May and June, resp.), and the spectral nudging experiment underestimates the precipitation $(\mathrm{ME}=-10.07 \mathrm{~mm}$ and $\mathrm{ME}=$ $-15.35 \mathrm{~mm}$ in May and June, resp.). Although the correlation coefficient of the analysis nudging experiment is the lowest, the RMSE of precipitation decreased by $36.9 \%$ in May and by 
TABLE 1: Summary of the mean error (ME), the root mean square error (RMSE), the correlation coefficient (cc), PO, and NH at the threshold of $50 \mathrm{~mm}$ and $200 \mathrm{~mm}$ for monthly accumulated precipitation in May and June, 2011.

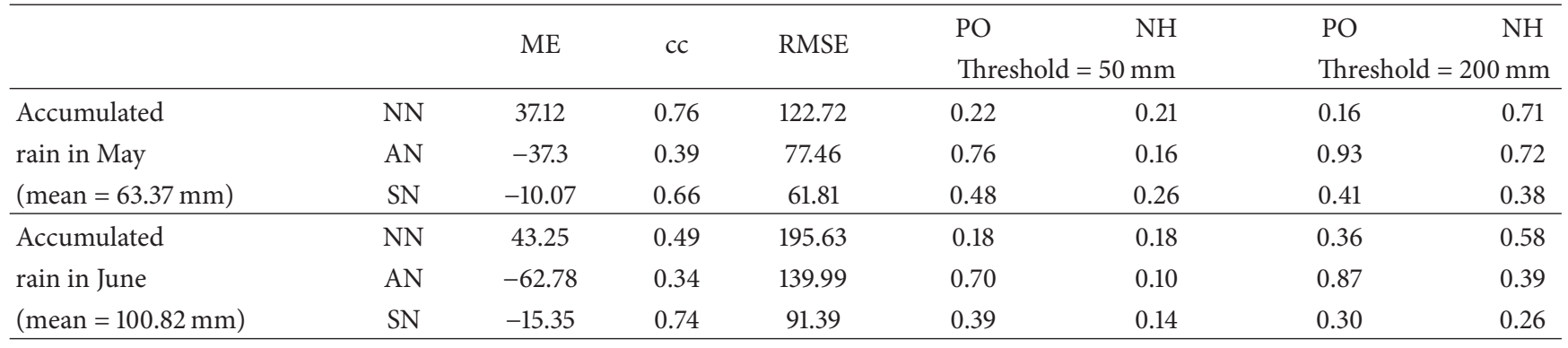

27.9\% in June. The precipitation bias for the spectral nudging experiment is generally smaller than that in the two other runs because the $\mathrm{ME}$ is much closer to 0 , the correlation coefficient is relatively higher, and the RMSE is reduced by $49.6 \%$ in May and $54.2 \%$ in June.

For monthly accumulated precipitation of less than $60 \mathrm{~mm}$, the no nudging experiment generally reproduces the precipitation magnitude and locations in May and June in terms of a BS closed to 1 (perfect $=1$ ), and a relative high TS. The spectral nudging experiment performs slightly worse, and the analysis nudging experiment performs the worst. For monthly accumulated precipitation between $60 \mathrm{~mm}$ and $100 \mathrm{~mm}$, the BS of the no nudging experiment is larger than 1, but its TS is relatively larger, indicating the no nudging experiment would overestimate the precipitation. The spectral experiment performs slightly better for BS. For monthly accumulated precipitation of more than $100 \mathrm{~mm}$, the no nudging experiment obviously overestimates the precipitation during May and June obviously, with the BS values being much larger than 1 and a relatively low TS value, especially for BS in May. The analysis nudging experiment underestimates the precipitation considerably because the BS value is smaller than 1 , and the TS is rather low, especially for extreme precipitation in May. The spectral nudging experiment performs best because the BS value is nearly 1, and the TS is relatively higher. This result suggests that the spectral nudging experiment can accurately characterize heavy rain during the flood season.

To compare the daily variations, the ME, RMSE, cc, and BS and TS from the model-simulated daily accumulated precipitation are displayed in Figure 4 (the precipitation from the real time analysis system of the $0.25^{\circ}$ grids daily precipitation dataset over China (1st edition) obtained from the NMIC was chosen as the observation dataset). Figure 4(a) shows that the no nudging experiment overestimates precipitation almost every day, but the analysis nudging experiment underestimates precipitation. The spectral nudging experiment provides better predictions than the no nudging experiment and the analysis nudging experiment because the ME and BS are closer to 1, the $\mathrm{cc}$ and TS are relatively higher for most days, and the RMSE of the spectral nudging experiment is relatively smaller. These results are consistent with the results shown in Figures 2 and 3 and Table 1. In addition, the phase of the errors in the no nudging experiment is often not aligned with the errors in the spectral nudging experiment and always overestimates precipitation, especially when the BS value is greater than 3 . This result suggests that the individual weather events in the no nudging experiment may be misrepresented, which indicates that they may inaccurately characterize prolonged periods of heavy rain and contribute to more flooding. Similarly, the analysis nudging experiment may inaccurately characterize dry spells and contribute to more droughts. The spectral nudging experiment is a good choice for dynamical downscaling when focusing on precipitation.

\subsection{Verification of Conventional Meteorological Elements Near} the Surface. The monthly mean conventional meteorological elements near the surface, including $2 \mathrm{~m}$ temperature (T2), surface pressure (Ps), $10 \mathrm{~m}$ wind speed (wsp10), and $2 \mathrm{~m}$ relative humidity $\left(\mathrm{RH}_{2}\right)$, are computed for each of the three WRF simulations and compared with the observations. Figure 5 shows a comparison of the $2 \mathrm{~m}$ temperature data for May 2011 and the $2 \mathrm{~m}$ relative humidity for June 2011. All of the three WRF simulations reproduce the $2 \mathrm{~m}$ temperature distribution, but the results of the $2 \mathrm{~m}$ relative humidity are relative poor. The no nudging experiment shows a warm bias in northern China, the Yangtze River delta, southern China, southwestern China, and the Taklimakan desert and a slight cold bias in the Tibet Plateau. The two nudging experiments effectively decrease the warm bias of the $2 \mathrm{~m}$ temperature. The no nudging experiment shows a heavy dry bias in northeast China, northwestern China, and northern China. Both the nudging experiments decrease the dry bias of the $2 \mathrm{~m}$ relative humidity. The analysis nudging experiment performs much better than the spectral nudging experiment and reproduces the distribution, although it still has a slight dry bias.

The related statistical verification techniques are shown in Table 2. The bias of the monthly mean conventional meteorological elements is more pronounced in the no nudging experiment, in which the warm and dry bias exceeds $3.2^{\circ} \mathrm{C}$ and $15 \%$ and the biases of the surface pressure and $10 \mathrm{~m}$ wind speed exceed $-7.0 \mathrm{hPa}$ and $1.7 \mathrm{~m} / \mathrm{s}$, respectively. The evolutions of the ME, RMSE, and cc of some model-simulated daily conventional meteorological elements near the surface are displayed in Figures 6 and 7. This further supports the results shown in Table 2 . Compared with daily variations, the no nudging experiment overestimates the $2 \mathrm{~m}$ temperature and $10 \mathrm{~m}$ wind speeds and underestimates the surface pressure and $2 \mathrm{~m}$ relative humidity nearly every day. On special days, the biases of the $2 \mathrm{~m}$ temperature, surface pressure, $10 \mathrm{~m}$ 


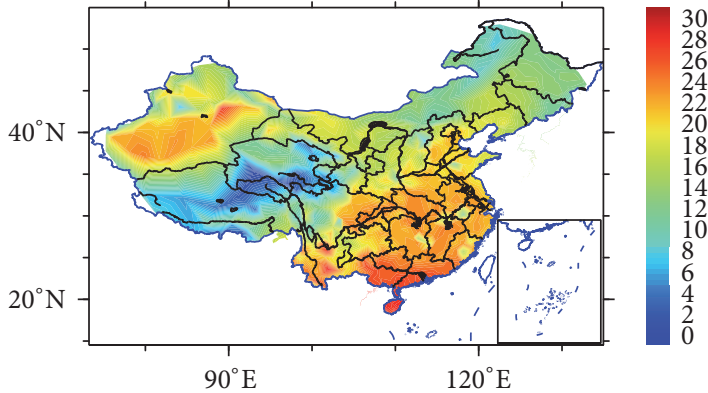

(a) Obs_May

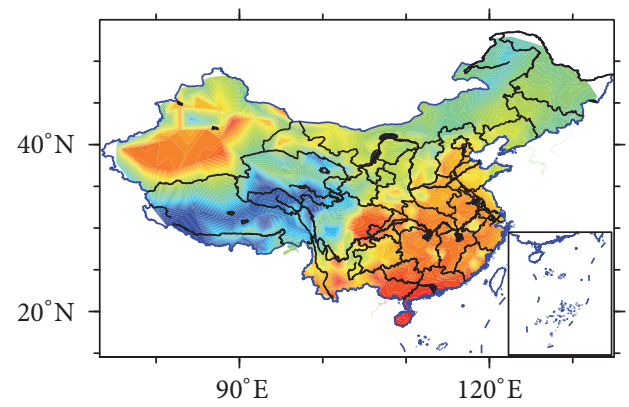

(c) AN_May

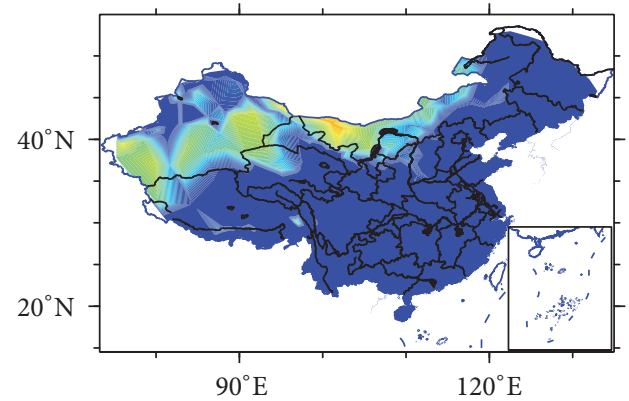

(e) Obs_June

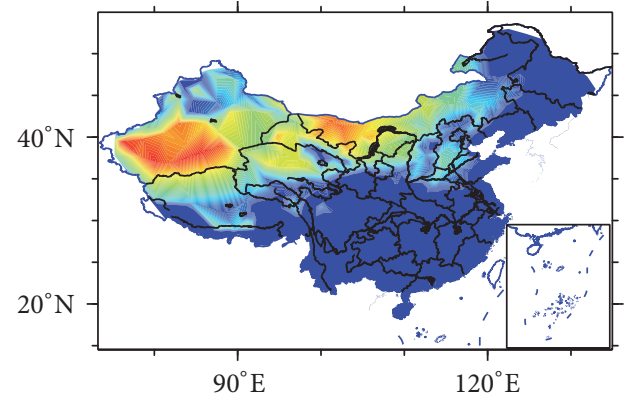

(g) AN_June

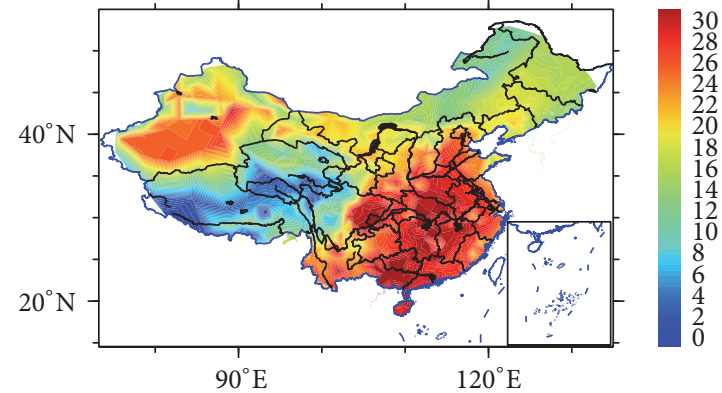

(b) NN_May
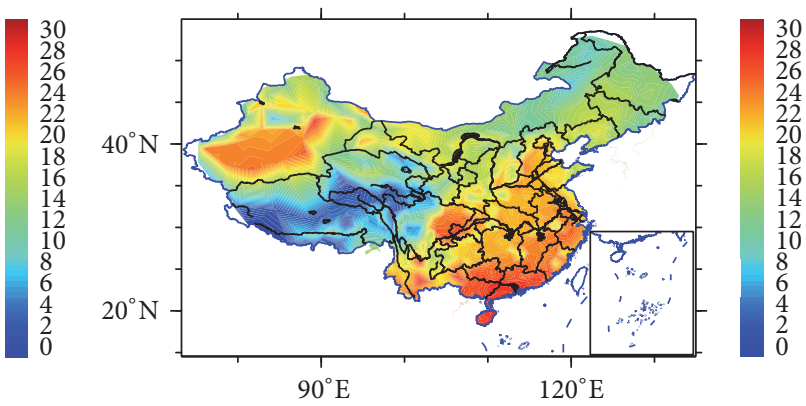

(d) SN_May
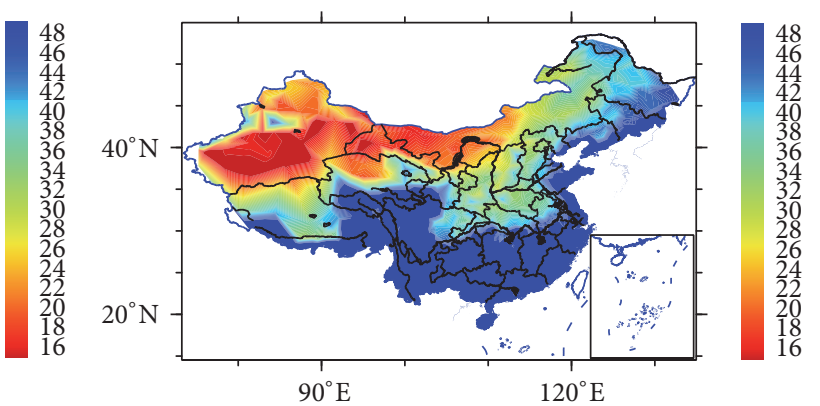

(f) NN_June

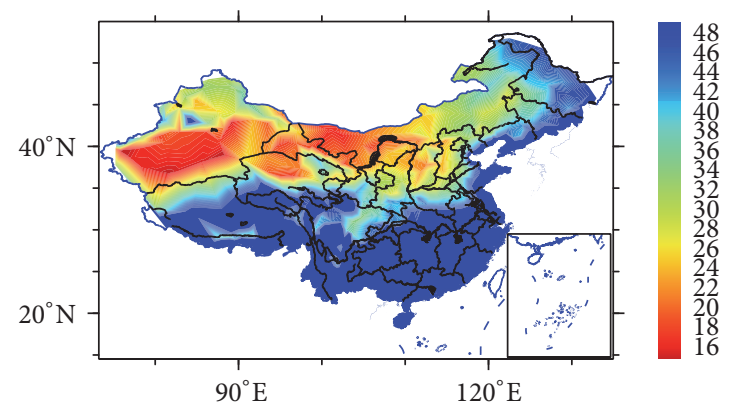

(h) SN_June

FIGURE 5: Comparison of $2 \mathrm{~m}$ temperature $\left({ }^{\circ} \mathrm{C}\right)$ in May 2011 ((a)-(d)) and 2 m relative humidity (\%) in June 2011 ((e)-(h)): (a), (e) the observed value, (b), (f) WRF simulated results with no nudging (NN), (c), (g) WRF simulated results with analysis nudging (AN), and (d), (h) WRF simulated results with spectral nudging $(\mathrm{SN})$.

wind speed, and $2 \mathrm{~m}$ relative humidity are greater than $5.5^{\circ} \mathrm{C}$, $-9.4 \mathrm{hPa}, 2.7 \mathrm{~m} / \mathrm{s}$, and $-24 \%$, respectively. The two nudging experiments decrease the daily bias. The analysis nudging experiment and the spectral nudging experiment perform similarly when simulating the surface pressure. The analysis nudging experiment performs much better for the $10 \mathrm{~m}$ wind speed and especially for the $2 \mathrm{~m}$ relative humidity. The analysis nudging experiment is a good choice for dynamical downscaling when focusing on conventional meteorological elements near the surface. 
TABLE 2: Summary of the ME, RMSE, and cc for monthly averaged conventional meteorological elements near the surface, including the $2 \mathrm{~m}$ temperature $\left(\mathrm{T}_{2}\right)$, surface pressure $(\mathrm{Ps}), 10 \mathrm{~m}$ wind speed ( $\left.\mathrm{wsp}_{10}\right)$, and $2 \mathrm{~m}$ relative humidity $\left(\mathrm{RH}_{2}\right)$ in May and June, 2011.

\begin{tabular}{|c|c|c|c|c|c|c|c|}
\hline & \multicolumn{3}{|c|}{ May } & \multicolumn{3}{|c|}{ June } \\
\hline & & $\mathrm{ME}$ & RMSE & $\mathrm{cc}$ & ME & RMSE & $\mathrm{cc}$ \\
\hline \multirow{3}{*}{$\mathrm{T}_{2}$} & NN & 3.21 & 4.33 & 0.94 & 3.88 & 4.76 & 0.92 \\
\hline & AN & 0.19 & 1.69 & 0.97 & 0.67 & 1.76 & 0.96 \\
\hline & SN & 0.01 & 1.74 & 0.96 & 0.43 & 1.81 & 0.95 \\
\hline \multirow{3}{*}{ Ps } & NN & -7.06 & 18.08 & 0.99 & -8.28 & 19.00 & 0.99 \\
\hline & AN & -5.35 & 17.81 & 0.99 & -5.17 & 18.26 & 0.99 \\
\hline & SN & -5.33 & 17.82 & 0.99 & -5.06 & 18.23 & 0.99 \\
\hline \multirow{3}{*}{$\mathrm{wsp}_{10}$} & $\mathrm{NN}$ & 1.70 & 1.91 & 0.60 & 2.03 & 2.25 & 0.51 \\
\hline & AN & 0.36 & 0.84 & 0.70 & 0.35 & 0.87 & 0.64 \\
\hline & $\mathrm{SN}$ & 0.98 & 1.30 & 0.63 & 0.94 & 1.29 & 0.58 \\
\hline \multirow{3}{*}{$\mathrm{RH}_{2}$} & $\mathrm{NN}$ & -15.42 & 19.51 & 0.76 & -18.81 & 21.87 & 0.80 \\
\hline & AN & -7.18 & 10.30 & 0.90 & -8.88 & 11.64 & 0.90 \\
\hline & $\mathrm{SN}$ & -15.07 & 18.35 & 0.79 & -17.19 & 20.08 & 0.85 \\
\hline
\end{tabular}

\subsection{Conventional Meteorological Elements for Different Height} Level Verification. The monthly mean conventional meteorological elements at the different heights of the three WRF simulations are also compared against the observational data. Figures $8(\mathrm{a}), 8(\mathrm{~b})$, and $8(\mathrm{c})$ compare the biases in the $500 \mathrm{hPa}$ geopotential height and circulation, and Figures $8(\mathrm{~d}), 8(\mathrm{e})$, and $8(\mathrm{f})$ compare the biases in the $700 \mathrm{hPa}$ water vapor mixing ratio and circulation for June, 2011. The results from the no nudging experiment show remarkable biases. Figure 8(a) shows a major high-pressure system located over northwestern China and northern China, where relatively irregular and weak anticyclones are located; however, the difference in circulation is relatively small. Major low-pressure and cyclonic bias occurs over southwestern China, southern China, and the East China Seaboard centered on Taiwan. Moreover, a low-pressure and cyclonic system also occurs in northeastern China. All of the above results indicate biases in the large-scale circulation. Figure 8(d) shows a major high water vapor mixing ratio belt in southwestern China, in the northern China region, and in northeastern China and a major low water vapor mixing ratio region in other regions. Moreover, differences in circulation are also obvious.

The biases in the two nudging experiments are considerably smaller, especially for the analysis nudging experiment. The analysis nudging experiment shows the smallest bias for circulations and water vapor mixing ratio at $500 \mathrm{hPa}$ and $700 \mathrm{hPa}$ (Figures 8(b) and 8(e)). The bias of the $500 \mathrm{hPa}$ geopotential height simulated by the spectral nudging experiment is similar to that in the analysis nudging experiment (Figures $8(\mathrm{~b})$ and $8(\mathrm{c})$ ), but the bias in the circulation and $700 \mathrm{hPa}$ water vapor mixing ratio is larger (Figures $8(\mathrm{c}$ ) and $8(\mathrm{f})$ ). Figure $8(\mathrm{f})$ shows low water vapor mixing ratios throughout China.

The related statistical verification techniques of all monthly averaged meteorological elements at different height levels are calculated, and the bias is more pronounced in the no nudging experiment (table not shown). For further analysis, the evolutions of the ME, RMSE, and cc of some model-simulated daily conventional meteorological elements at different height levels are displayed in Figure 9. Compared with the daily variations, the no nudging experiment generally overestimates the $500 \mathrm{hPa}$ geopotential height and temperature, and the $700 \mathrm{hPa}$ water vapor mixing ratio, the $850 \mathrm{hPa}$ wind speed, and the RMSE are the largest. The spectral nudging experiment performs similarly to the analysis nudging experiment in the simulations with $500 \mathrm{hPa}$ geopotential height and temperature; however, the analysis nudging experiment still performs slightly better. Regarding the $700 \mathrm{hPa}$ water vapor mixing ratio and the $850 \mathrm{hPa}$ wind speed, the analysis nudging experiment performs the best, especially for a water vapor mixing ratio at $700 \mathrm{hPa}$, which the spectral nudging experiment heavily underestimates.

In conclusion, analysis nudging experiment performs better regarding the performance of conventional meteorological elements simulations, especially for air humidity and circulation systems at different height levels. Analysis nudging is applied to the horizontal wind components, potential temperature, and water vapor mixing ratio and spectral nudging is applied to the horizontal wind components, potential temperature, and geopotential height. The field moisture is directly adjusted when using analysis nudging in the WRF. Thus, it is understandable why analysis nudging performs better for air humidity.

In addition, although analysis nudging and spectral nudging both directly adjust the wind field and spectral nudging directly adjusts the height field, for spectral nudging, the atmospheric state is forced to accept the analyses for large scales while smaller scales are left to be determined by the regional model itself [34]; however, analysis nudging is conducted to force the atmospheric state at both the large scales and small scales [33]. Thus, the performance of the analysis nudging experiment is better for simulating circulation systems, such as wind speed, because the circulation systems are influenced by both large-scale circulation and the local scale characteristic, such as local mountains and lakes. 


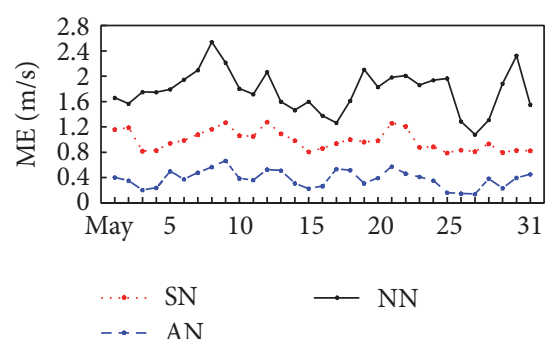

(a)

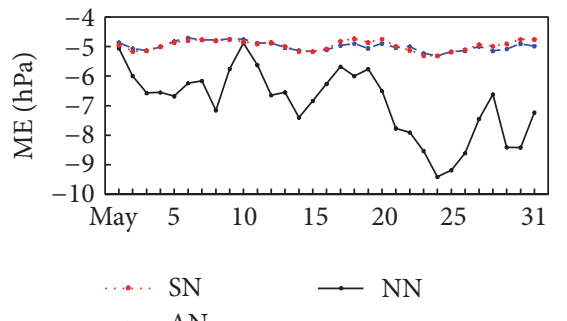

(d)

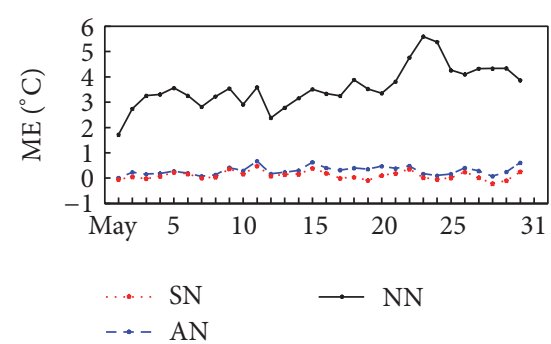

(g)

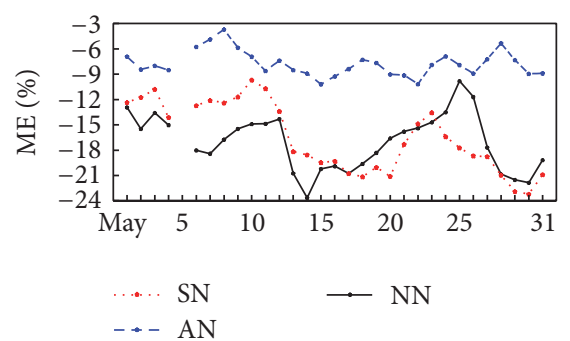

(j)

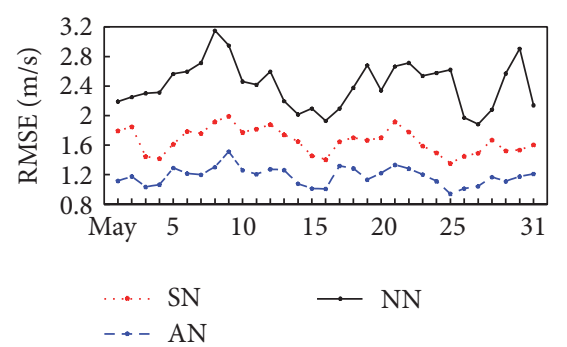

(b)

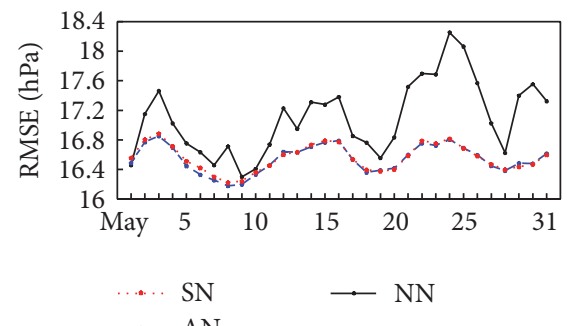

(e)

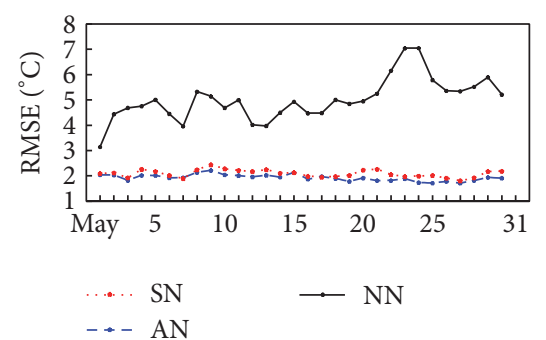

(h)

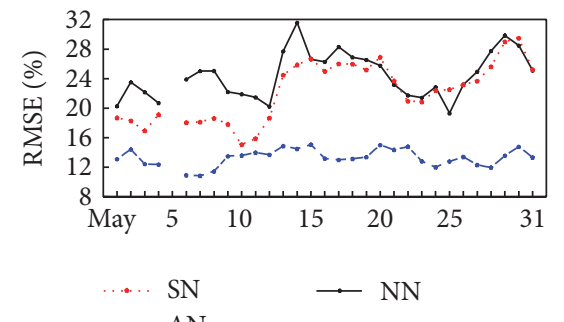

(k)

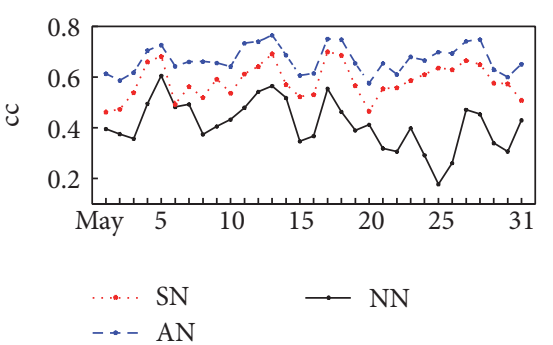

(c)

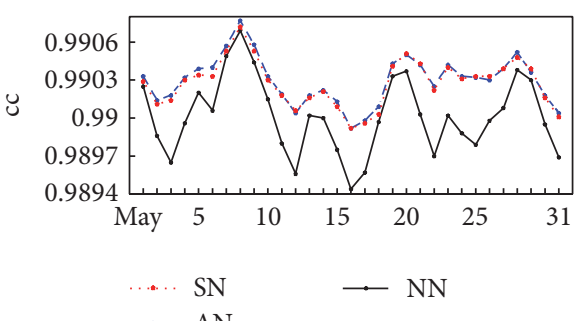

(f)

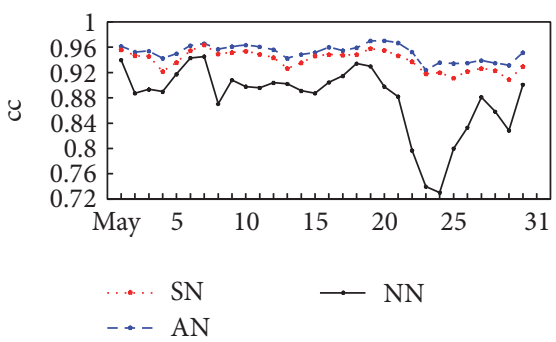

(i)

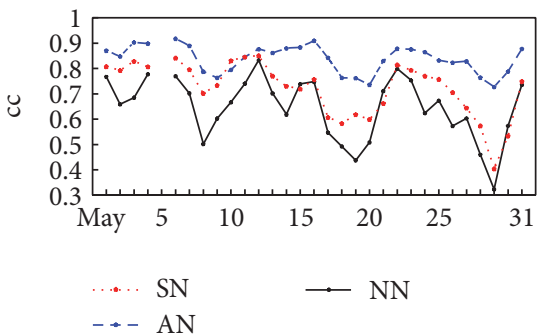

(l)

FIGURE 6: Time series plots of related statistical verification techniques for daily averaged conventional meteorological elements near the surface for May, 2011.

What is more, the spectral nudging experiment performs much better for the precipitation than the analysis nudging experiment that the former indicates a lower bias in the precipitation simulation regarding area coverage and magnitude. The reason is that spectral nudging balances the performance of the simulation at the large and small scales much better and performs better for horizontal kinetic energy, which strongly affects clouds and precipitation [29]. Therefore, for precipitation, which is a product of various factors, spectral nudging experiment performs better. Besides, the better simulation of precipitation achieved by the spectral nudging experiment suggests that directly nudging moisture may not be necessary for improving the precipitation simulations, which is consistent with the results of [29].

\section{Conclusions}

In this paper, the performances of nudging, including analysis nudging and spectral nudging on regional climate dynamical downscaling, are compared. Using the WRF model as a RCM, three continuous sensitivity experiments (with no nudging, analysis nudging, and spectral nudging) are conducted to investigate which nudging techniques perform better when downscaling the NCEP data using the WRF model over China. Considering the resolution needs and computational expense, all experiments are conducted between May and June 2011 at a resolution of $6 \mathrm{~km}$.

The simulation with no nudging overestimates the maximum precipitation magnitude and locations and simulates 


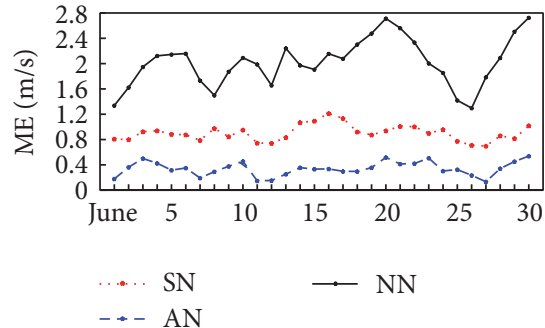

(a)

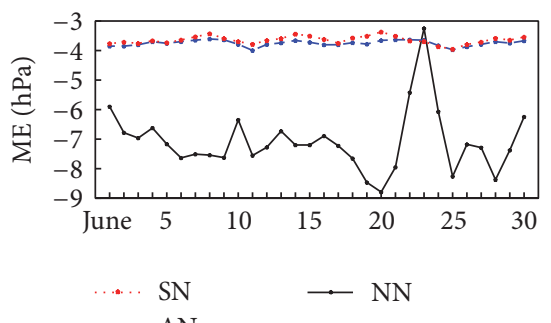

(d)

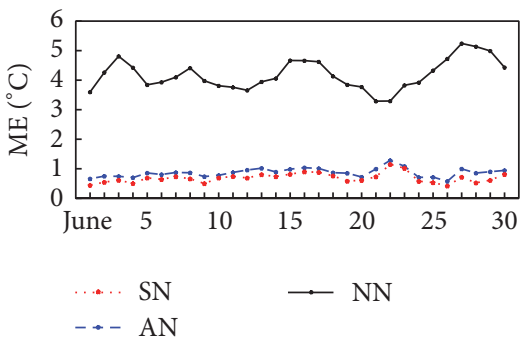

(g)

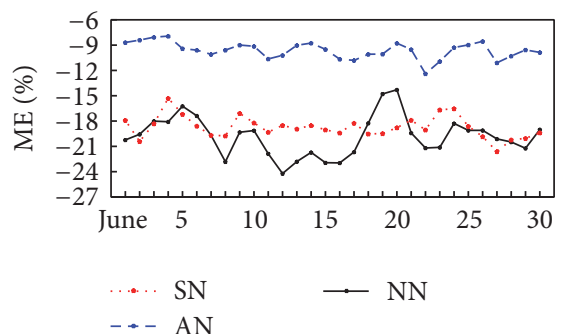

$(\mathrm{j})$

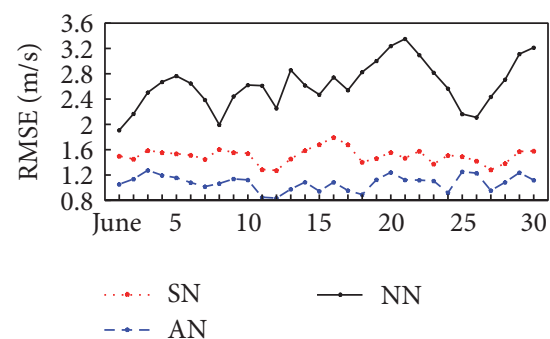

(b)

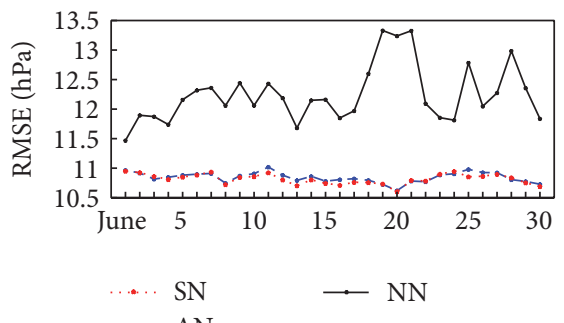

(e)

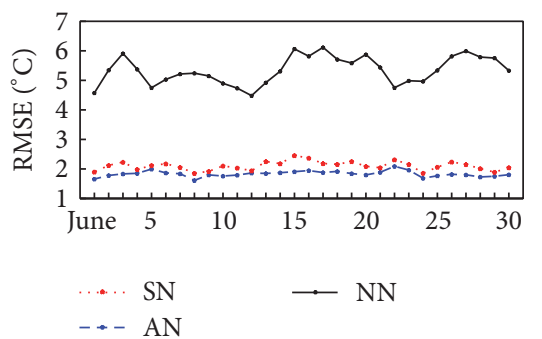

(h)

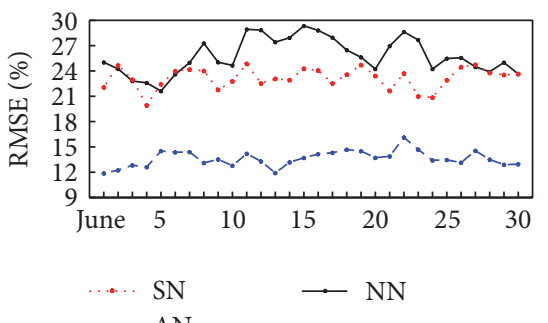

$(\mathrm{k})$

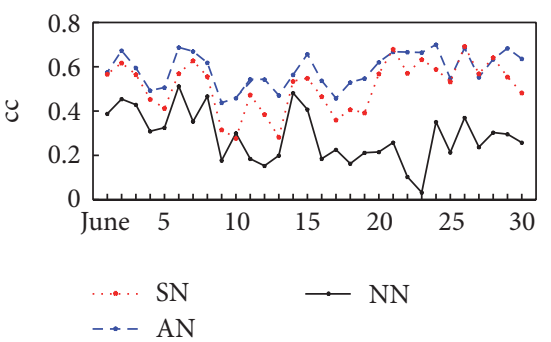

(c)

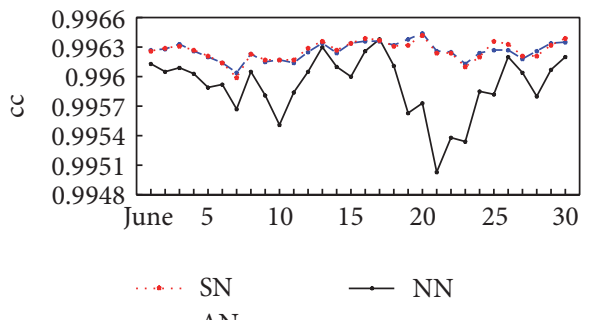

(f)

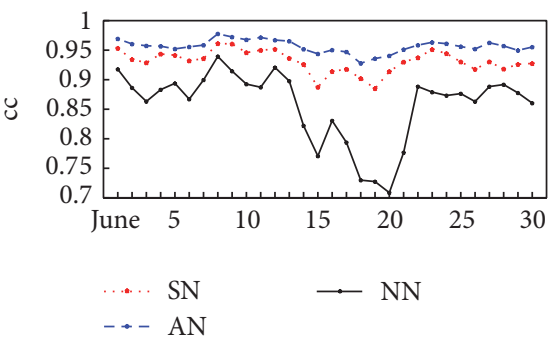

(i)

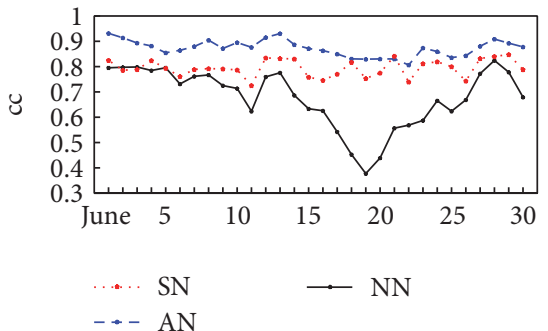

(l)

Figure 7: The same as Figure 6 but for June, 2011.

the incorrect locations (farther south of the Yangtze River delta region) of the maximum precipitation in June. The analysis nudging experiment generally underestimates the precipitation magnitude throughout China, and the spectral nudging experiment underestimates the precipitation magnitude in the region north of the Yangtze River. When comparing the daily variations, the no nudging experiment overestimates precipitation almost every day, but the analysis nudging experiment underestimates the precipitation. The spectral nudging experiment indicates a lower bias in the precipitation simulation regarding area coverage and magnitude and performs better than the analysis nudging experiment.
Moreover, the results show that both of the nudging experiments decrease the bias of conventional meteorological elements near the surface and at different heights during the regional climate dynamical downscaling process relative to the experiment with no nudging. In detail, the performances of the two nudging experiments are similar in the simulation of $2 \mathrm{~m}$ temperature, surface pressure, geopotential height, and temperature at different levels, but the analysis nudging experiment performs better for the $10 \mathrm{~m}$ wind speed, $2 \mathrm{~m}$ relative humidity, air humidity, and circulation systems at different heights.

However, our numerical experiments are based on only one model simulation covering a short period of two months 


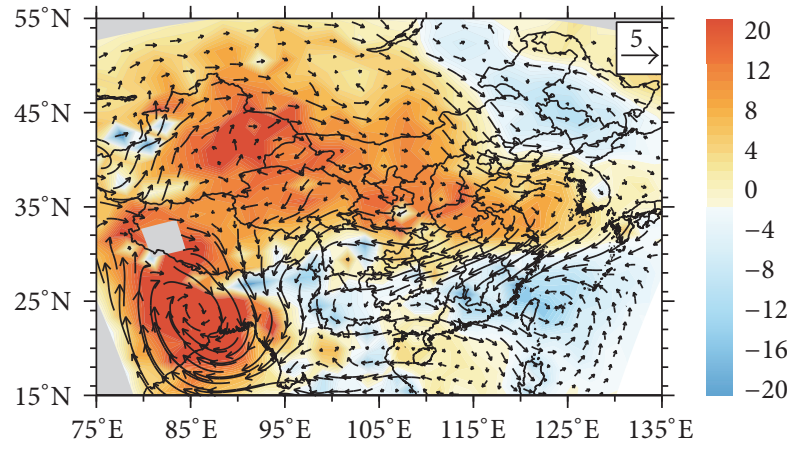

(a) NN-ERA

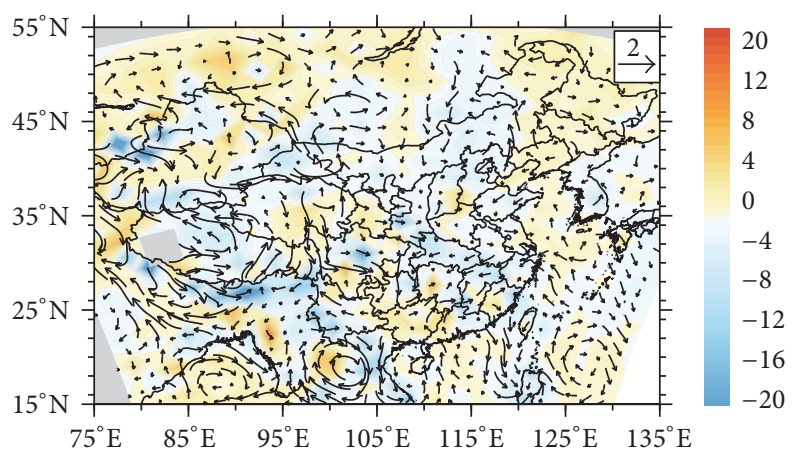

(c) SN-ERA

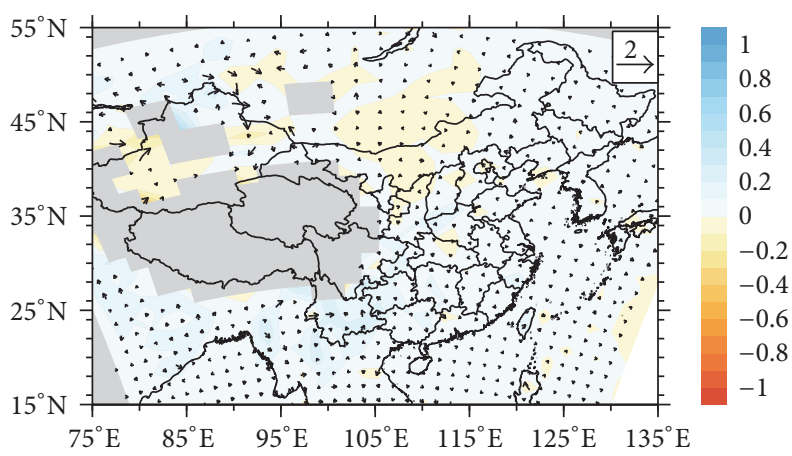

(e) AN-ERA

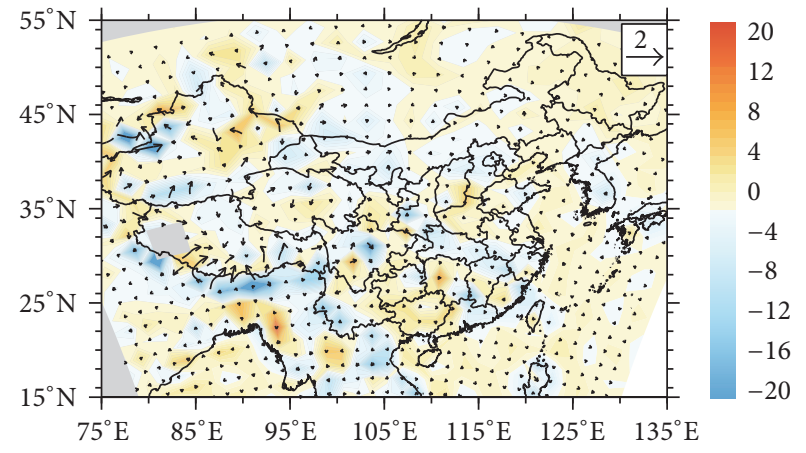

(b) AN-ERA

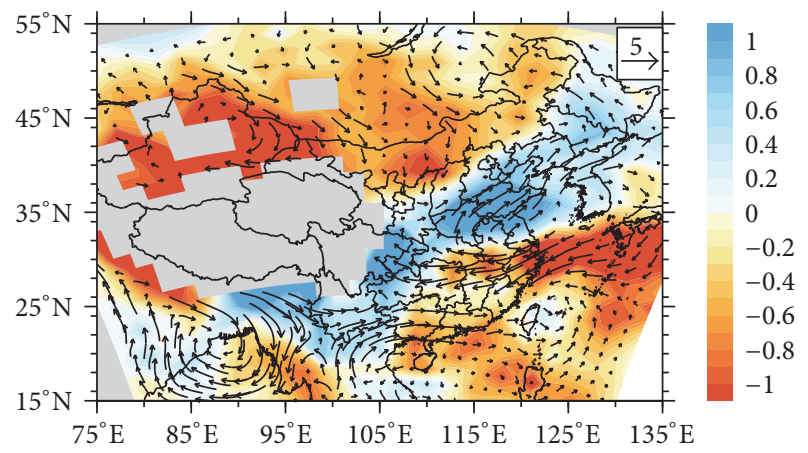

(d) NN-ERA

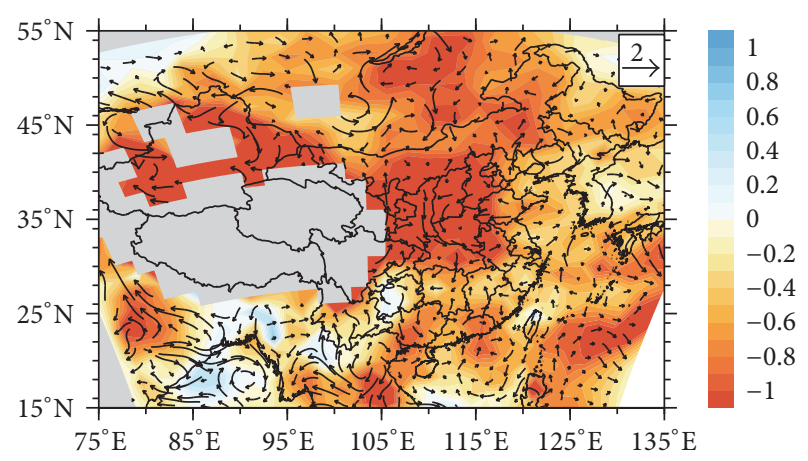

(f) SN-ERA

Figure 8: The model biases of monthly mean geopotential height (shading in units of meter) and horizontal winds (vector in units of $5 \mathrm{~m} / \mathrm{s}$ with $\mathrm{NN}$, but $2 \mathrm{~m} / \mathrm{s}$ with $\mathrm{AN}$ and $\mathrm{SN}$ ) at $500 \mathrm{hPa}((\mathrm{a})-(\mathrm{c})$ ) and monthly mean water vapor mixing ratio (shading in units of $\mathrm{q} / \mathrm{kg}$ ) and horizontal winds at $700 \mathrm{hPa}((\mathrm{d})-(\mathrm{f}))$ in June, 2011. Respectively, (a) and (d) are the biases simulated with the no nudging experiment (NN), (b) and (e) are the biases simulated with the analysis nudging experiment (AN), and (c) and (f) are the biases simulated with the spectral nudging experiment $(\mathrm{SN})$. All the biases are defined by the departure of WRF simulations from ERA-IN. Gray zones are the missing value masked by the topography.

at a convection-permitting resolution of May and June, 2011. Besides, the different nudging coefficients, wave numbers, durations, and nudging different variables would affect the performance of nudging. Long-term simulations with multiple models and more experiments with different setting options of nudging and coarse resolution are needed to validate the robustness of the conclusions obtained here. Nevertheless, the issues addressed here may provide useful insight for future design of RCMs intercomparison project.

\section{Competing Interests}

The authors declare that there are no competing interests regarding the publication of this paper.

\section{Acknowledgments}

This work was supported by the Key Program of the National Nature Science Foundation of China (41330527), the National 


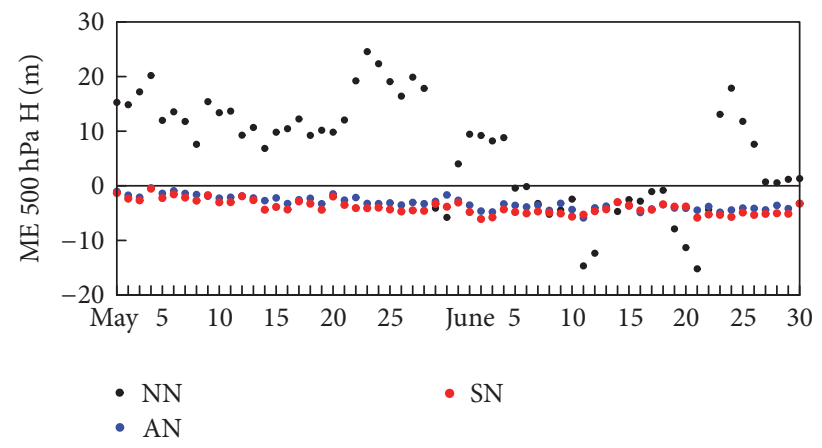

(a)

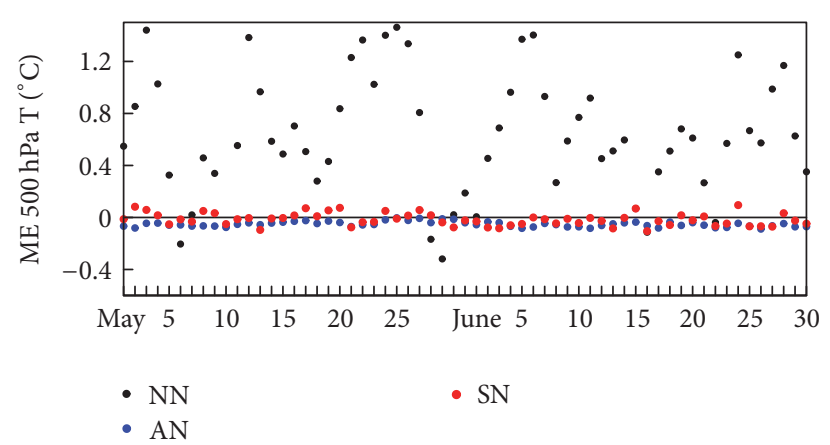

(c)

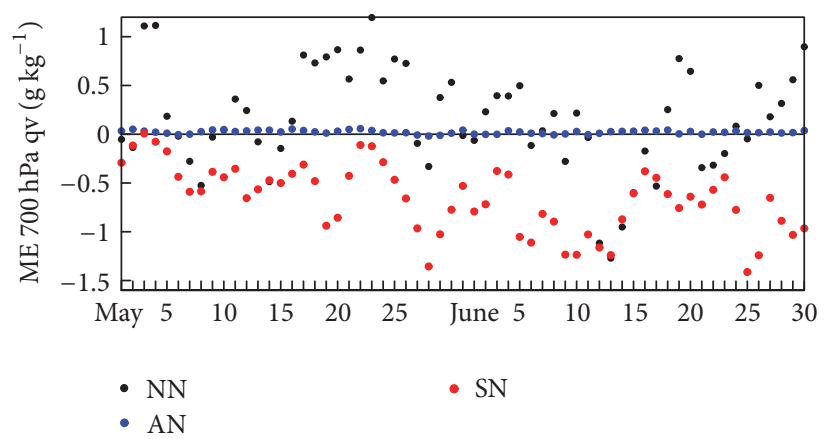

(e)

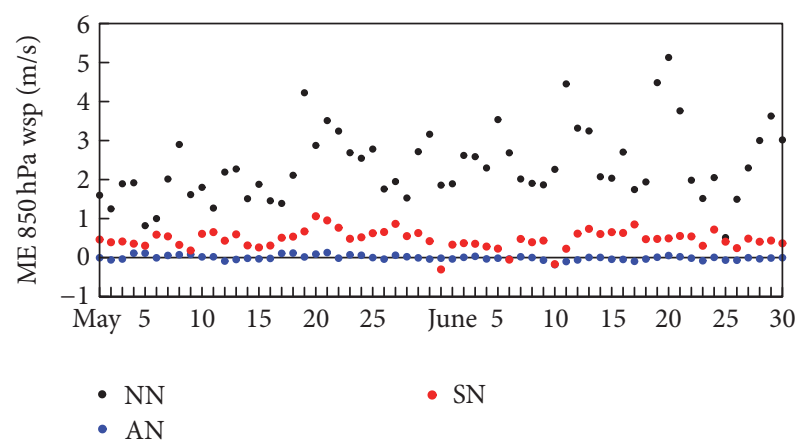

(g)

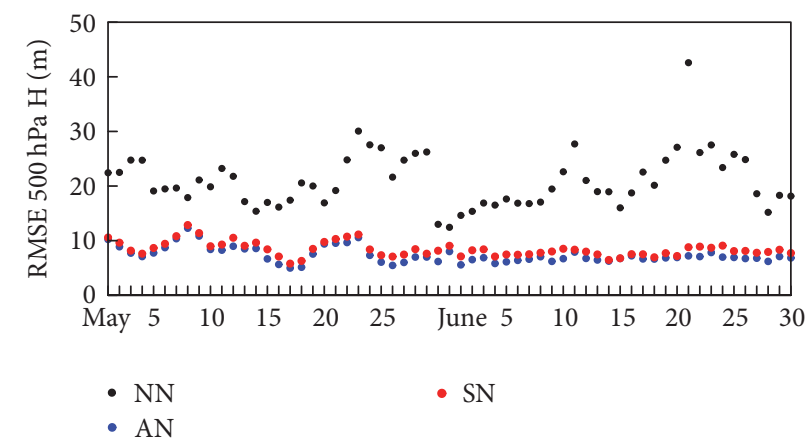

(b)

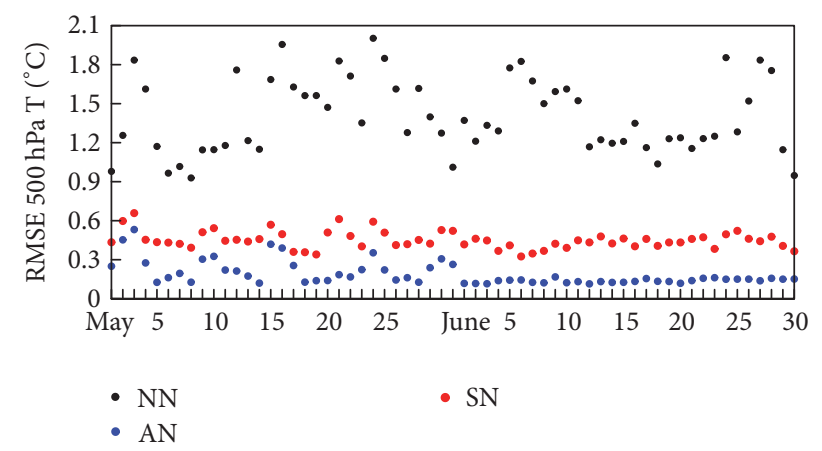

(d)

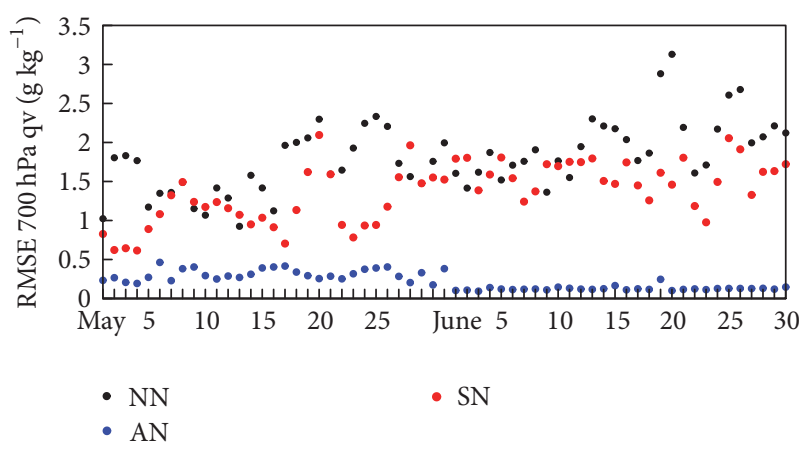

(f)

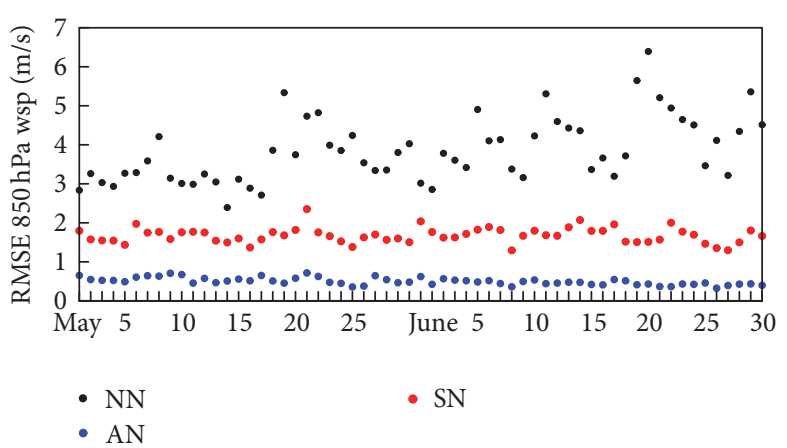

(h)

Figure 9: Time series plots of the ME and RMSE between the observations and downscaling results for $500 \mathrm{hPa}$ geopotential height (a, b) and temperature $(\mathrm{c}, \mathrm{d}), 700 \mathrm{hPa}$ water vapor mixing ratio $(\mathrm{e}, \mathrm{f})$, and $850 \mathrm{hPa}$ wind speed $(\mathrm{g}, \mathrm{h})$ for May and June 2011. 
Nature Science Foundation of China (41675098), and the Fundamental Research Funds for the Central Universities (lzujbky-2015-k03). The authors gratefully thank the Monthly Tropical Rainfall Measuring Mission and the National Meteorological Information Center (NMIC) of the China Meteorological Administration for providing the observation data.

\section{References}

[1] IPCC, IPCC, 2013: Climate Change 2013: The Physical Science Basis. Contribution of Working Group I to the Fifth Assessment Report of the Intergovernmental Panel on Climate Change, IPCC, 2013.

[2] F. Giorgi, "Regional climate modeling: status and perspectives," Journal de Physique IV (Proceedings), EDP Sciences, vol. 139, pp. 101-118, 2006.

[3] L. R. Leung, L. O. Mearns, F. Giorgi, and R. L. Wilby, "Regional climate research," Bulletin of the American Meteorological Society, vol. 84, no. 1, pp. 89-95, 2003.

[4] Y. Wang, L. R. Leung, J. L. McGregor et al., "Regional climate modeling: progress, challenges, and prospects," Journal of the Meteorological Society of Japan, vol. 82, no. 6, pp. 1599-1628, 2004.

[5] F. Giorgi and W. J. Gutowski, "Regional dynamical downscaling and the CORDEX initiative," Annual Review of Environment and Resources, vol. 40, pp. 467-490, 2015.

[6] R. Laprise, "Comment on 'the added value to global model projections of climate change by dynamical downscaling: a case study over the continental U.S. using the GISS-ModelE2 and WRF models' by Racherla et al.," Journal of Geophysical Research: Atmospheres, vol. 119, no. 7, pp. 3877-3881, 2014.

[7] S. Antic, R. Laprise, B. Denis, and R. de Elía, “Testing the downscaling ability of a one-way nested regional climate model in regions of complex topography," Climate Dynamics, vol. 23, no. 5, pp. 473-493, 2004.

[8] B. H. Lynn, R. Healy, and L. M. Druyan, "Quantifying the sensitivity of simulated climate change to model configuration," Climatic Change, vol. 92, no. 3-4, pp. 275-298, 2009.

[9] P. Axelsson, M. Tjernström, S. Söderberg, and G. Svensson, "An ensemble of arctic simulations of the AOE-2001 field experiment," Atmosphere, vol. 2, no. 2, pp. 146-170, 2011.

[10] J. Crétat, B. Pohl, Y. Richard, and P. Drobinski, "Uncertainties in simulating regional climate of Southern Africa: sensitivity to physical parameterizations using WRF," Climate Dynamics, vol. 38, no. 3-4, pp. 613-634, 2012.

[11] A. Pfeiffer and G. Zängl, "Validation of climate-mode MM5simulations for the European Alpine Region," Theoretical and Applied Climatology, vol. 101, no. 1, pp. 93-108, 2010.

[12] S. Seneviratne, N. Nicholls, D. Easterling et al., "Changes in climate extremes and their impacts on the natural physical environment," in Managing the Risks of Extreme Events and Disasters to Advance Climate Change Adaptation, pp. 109-230, Cambridge University Press, Cambridge, UK, 2012.

[13] M. Tjernström, J. Sedlar, and M. D. Shupe, "How well do regional climate models reproduce radiation and clouds in the arctic? An evaluation of ARCMIP simulations," Journal of Applied Meteorology and Climatology, vol. 47, no. 9, pp. 24052422, 2008.

[14] K. Wyser, C. G. Jones, P. Du et al., "An evaluation of Arctic cloud and radiation processes during the SHEBA year: simulation results from eight Arctic regional climate models," Climate Dynamics, vol. 30, no. 2-3, pp. 203-223, 2008.

[15] J. C.-F. Lo, Z.-L. Yang, and R. A. Pielke Sr., "Assessment of three dynamical climate downscaling methods using the Weather Research and Forecasting (WRF) model," Journal of Geophysical Research Atmospheres, vol. 113, no. 9, Article ID D09112, 2008.

[16] B. Wang and H. Yang, "Hydrological issues in lateral boundary conditions for regional climate modeling: simulation of east asian summer monsoon in 1998," Climate Dynamics, vol. 31, no. 4, pp. 477-490, 2008.

[17] H. Yang and B. Wang, "Reduction of systematic biases in regional climate downscaling through ensemble forcing," Climate Dynamics, vol. 38, no. 3-4, pp. 655-665, 2012.

[18] S. Antic, R. Laprise, B. Denis, and R. De Elía, "Testing the downscaling ability of a one-way nested regional climate model in regions of complex topography," Climate Dynamics, vol. 26, no. 2-3, pp. 305-325, 2006.

[19] A. Di Luca, R. de Elía, and R. Laprise, "Potential for added value in precipitation simulated by high-resolution nested regional climate models and observations," Climate Dynamics, vol. 38, no. 5-6, pp. 1229-1247, 2012.

[20] X. Gao, J. Li, and S. Sorooshian, "Modeling intraseasonal features of 2004 North American monsoon precipitation," Journal of Climate, vol. 20, no. 9, pp. 1882-1896, 2007.

[21] P. Lucas-Picher, F. Boberg, J. H. Christensen, and P. Berg, "Dynamical downscaling with reinitializations: a method to generate finescale climate datasets suitable for impact studies," Journal of Hydrometeorology, vol. 14, no. 4, pp. 1159-1174, 2013.

[22] D. H. Cha, C. S. Jin, D. K. Lee, and Y. H. Kuo, "Impact of intermittent spectral nudging on regional climate simulation using Weather Research and Forecasting model," Journal of Geophysical Research: Atmospheres, vol. 116, no. 10, 2011.

[23] H. Omrani, P. Drobinski, and T. Dubos, "Optimal nudging strategies in regional climate modelling: investigation in a BigBrother experiment over the European and Mediterranean regions," Climate Dynamics, vol. 41, no. 9-10, pp. 2451-2470, 2013.

[24] Z. Xu and Z.-L. Yang, "An improved dynamical downscaling method with GCM bias corrections and its validation with 30 years of climate simulations," Journal of Climate, vol. 25, no. 18, pp. 6271-6286, 2012.

[25] K. Yoshimura and M. Kanamitsu, "Incremental correction for the dynamical downscaling of ensemble mean atmospheric fields," Monthly Weather Review, vol. 141, no. 9, pp. 3087-3101, 2013.

[26] A. Alexandru, R. de Elia, and R. Laprise, "Internal variability in regional climate downscaling at the seasonal scale," Monthly Weather Review, vol. 135, no. 9, pp. 3221-3238, 2007.

[27] L.-P. Caron, C. G. Jones, and K. Winger, "Impact of resolution and downscaling technique in simulating recent Atlantic tropical cylone activity," Climate Dynamics, vol. 37, no. 5-6, pp. 869$892,2011$.

[28] F. De Sales and Y. Xue, "Assessing the dynamic-downscaling ability over South America using the intensity-scale verification technique," International Journal of Climatology, vol. 31, no. 8, pp. 1205-1221, 2011.

[29] P. Liu, A. P. Tsimpidi, Y. Hu, B. Stone, A. G. Russell, and A. Nenes, "Differences between downscaling with spectral and grid nudging using WRF," Atmospheric Chemistry and Physics, vol. 12, no. 8, pp. 3601-3610, 2012. 
[30] K. Mabuchi, Y. Sato, and H. Kida, "Verification of the climatic features of a regional climate model with BAIM," Journal of the Meteorological Society of Japan. Series II, vol. 80, no. 4, pp. 621644, 2002.

[31] G. Miguez-Macho, G. L. Stenchikov, and A. Robock, "Regional climate simulations over North America: interaction of local processes with improved large-scale flow," Journal of Climate, vol. 18, no. 8, pp. 1227-1246, 2005.

[32] J. Wang and V. R. Kotamarthi, "Assessment of dynamical downscaling in near-surface fields with different spectral nudging approaches using the nested regional climate model (NRCM)," Journal of Applied Meteorology and Climatology, vol. 52, no. 7, pp. 1576-1591, 2013.

[33] D. R. Stauffer and N. L. Seaman, "Use of four-dimensional data assimilation in a limited-area mesoscale model. Part I: experiments with synoptic-scale data," Monthly Weather Review, vol. 118, no. 6, pp. 1250-1277, 1990.

[34] H. Von Storch, H. Langenberg, and F. Feser, "A spectral nudging technique for dynamical downscaling purposes," Monthly Weather Review, vol. 128, no. 10, pp. 3664-3673, 2000.

[35] G. Miguez-Macho, G. L. Stenchikov, and A. Robock, "Spectral nudging to eliminate the effects of domain position and geometry in regional climate model simulations," Journal of Geophysical Research D: Atmospheres, vol. 109, no. D13, 2004.

[36] K. M. Waldron, J. Paegle, and J. D. Horel, "Sensitivity of a spectrally filtered and nudged limited-area model to outer model options," Monthly Weather Review, vol. 124, no. 3, pp. 529-547, 1996.

[37] V. Misra, "Addressing the issue of systematic errors in a regional climate model," Journal of Climate, vol. 20, no. 5, pp. 801-818, 2007.

[38] T. L. Otte, C. G. Nolte, M. J. Otte, and J. H. Bowden, "Does nudging squelch the extremes in regional climate modeling?" Journal of Climate, vol. 25, no. 20, pp. 7046-7066, 2012.

[39] L. Separovic, R. de Elía, and R. Laprise, "Impact of spectral nudging and domain size in studies of RCM response to parameter modification," Climate Dynamics, vol. 38, no. 7-8, pp. 1325-1343, 2012.

[40] J. H. Bowden, T. L. Otte, C. G. Nolte, and M. J. Otte, "Examining interior grid nudging techniques using two-way nesting in the WRF model for regional climate modeling," Journal of Climate, vol. 25 , no. 8, pp. 2805-2823, 2012.

[41] F. Feser, "Enhanced detectability of added value in limited-area model results separated into different spatial scales," Monthly Weather Review, vol. 134, no. 8, pp. 2180-2190, 2006.

[42] F. Feser and H. Von Storch, "A spatial two-dimensional discrete filter for limited-area-model evaluation purposes," Monthly Weather Review, vol. 133, no. 6, pp. 1774-1786, 2005.

[43] B. Rockel, C. L. Castro, R. A. Pielke Sr., H. von Storch, and G. Leoncini, "Dynamical downscaling: assessment of model system dependent retained and added variability for two different regional climate models," Journal of Geophysical Research Atmospheres, vol. 113, no. D21, 2008.

[44] J. Winterfeldt and R. Weisse, "Assessment of value added for surface marine wind speed obtained from two regional climate models," Monthly Weather Review, vol. 137, no. 9, pp. 2955-2965, 2009.

[45] C. L. Castro, R. A. Pielke Sr., and G. Leoncini, "Dynamical downscaling: assessment of value retained and added using the Regional Atmopsheric Modeling System (RAMS)," Journal of Geophysical Research D: Atmospheres, vol. 110, no. 5, pp. 1-21, 2005.
[46] O. R. Bullock Jr., K. Alapaty, J. A. Herwehe et al., "An observation-based investigation of nudging in WRF for downscaling surface climate information to $12-\mathrm{km}$ grid spacing," Journal of Applied Meteorology and Climatology, vol. 53, no. 1, pp. 20-33, 2014.

[47] I. Guttler, I. Stepanov, G. Nikulin, C. Jones, and C. Brankovic, "Precipitation in complex orography simulated by the regional climate model RCA3," in Proceedings of the 3rd Lund RegionalScale Climate Modelling Workshop, 21st Century Challenges in Regional Climate Modelling, Paper Presented at International Baltic Earth Secretariat Publication 3, Baltic Earth, Lund, Sweden, June 2014.

[48] S. Pryor, G. Nikulin, and C. Jones, "Influence of spatial resolution on regional climate model derived wind climates," Journal of Geophysical Research: Atmospheres, vol. 117, no. 3, 2012.

[49] R. Vautard, A. Gobiet, D. Jacob et al., “The simulation of European heat waves from an ensemble of regional climate models within the EURO-CORDEX project," Climate Dynamics, vol. 41, no. 9-10, pp. 2555-2575, 2013.

[50] A. Walther, J.-H. Jeong, G. Nikulin, C. Jones, and D. Chen, "Evaluation of the warm season diurnal cycle of precipitation over Sweden simulated by the Rossby Centre regional climate model RCA3," Atmospheric Research, vol. 119, pp. 131-139, 2013.

[51] Y. Xue, Z. Janjic, J. Dudhia, R. Vasic, and F. De Sales, "A review on regional dynamical downscaling in intraseasonal to seasonal simulation/prediction and major factors that affect downscaling ability," Atmospheric Research, vol. 147-148, pp. 68-85, 2014.

[52] W. J. Gutowski Jr., R. W. Arritt, S. Kawazoe et al., "Regional extreme monthly precipitation simulated by NARCCAP RCMs," Journal of Hydrometeorology, vol. 11, no. 6, pp. 1373-1379, 2010.

[53] M. Rojas, "Multiply nested regional climate simulation for southern South America: sensitivity to model resolution," Monthly Weather Review, vol. 134, no. 8, pp. 2208-2223, 2006.

[54] Y. Wakazuki, M. Nakamura, S. Kanada, and C. Muroi, "Climatological reproducibility evaluation and future climate projection of extreme precipitation events in the baiu season using a high-resolution non-hydrostatic RCM in comparison with an AGCM," Journal of the Meteorological Society of Japan, vol. 86, no. 6, pp. 951-967, 2008.

[55] H. Davies and R. E. Turner, "Updating prediction models by dynamical relaxation: an examination of the technique," Quarterly Journal of the Royal Meteorological Society, vol. 103, no. 436, pp. 225-245, 1977.

[56] W. Wang, C. Bruyère, M. Duda et al., Advanced Research WRF (ARW) Version 3 Modeling System User's Guide, Mesoscale and Microscale Meteorology Division, NCAR, 2012.

[57] S.-Y. Hong and J.-O. J. Lim, "The WRF single-moment 6class microphysics scheme (WSM6)," Asia-Pacific Journal of Atmospheric Sciences, vol. 42, no. 2, pp. 129-151, 2006.

[58] E. J. Mlawer, S. J. Taubman, P. D. Brown, M. J. Iacono, and S. A. Clough, "Radiative transfer for inhomogeneous atmospheres: RRTM, a validated correlated-k model for the longwave," Journal of Geophysical Research: Atmospheres, vol. 102, no. 14, pp. 16663-16682, 1997.

[59] J. Dudhia, "Numerical study of convection observed during the Winter Monsoon Experiment using a mesoscale twodimensional model," Journal of the Atmospheric Sciences, vol. 46, no. 20, pp. 3077-3107, 1989.

[60] Y. Noh, W. G. Cheon, S. Y. Hong, and S. Raasch, "Improvement of the K-profile model for the planetary boundary layer based 
on large eddy simulation data," Boundary-Layer Meteorology, vol. 107, no. 2, pp. 401-427, 2003.

[61] F. Chen and J. Dudhia, "Coupling an advanced land surfacehydrology model with the Penn-State-NCAR MM5 modeling system. Part II: preliminary model validation," Monthly Weather Review, vol. 129, no. 4, pp. 587-604, 2001.

[62] K. Kikuchi and B. Wang, "Diurnal precipitation regimes in the global tropics," Journal of Climate, vol. 21, no. 11, pp. 2680-2696, 2008.

[63] H. Chen, W. Yuan, J. Li, and R. Yu, "A possible cause for different diurnal variations of warm season rainfall as shown in station observations and TRMM 3B42 data over the southeastern Tibetan plateau," Advances in Atmospheric Sciences, vol. 29, no. 1, pp. 193-200, 2012.

[64] W. Yuan, R. Yu, M. Zhang, W. Lin, H. Chen, and J. Li, "Regimes of diurnal variation of summer rainfall over subtropical East Asia," Journal of Climate, vol. 25, no. 9, pp. 3307-3320, 2012.

[65] D. P. Dee, S. M. Uppala, A. J. Simmons et al., “The ERA-Interim reanalysis: configuration and performance of the data assimilation system," Quarterly Journal of the Royal Meteorological Society, vol. 137, no. 656, pp. 553-597, 2011. 

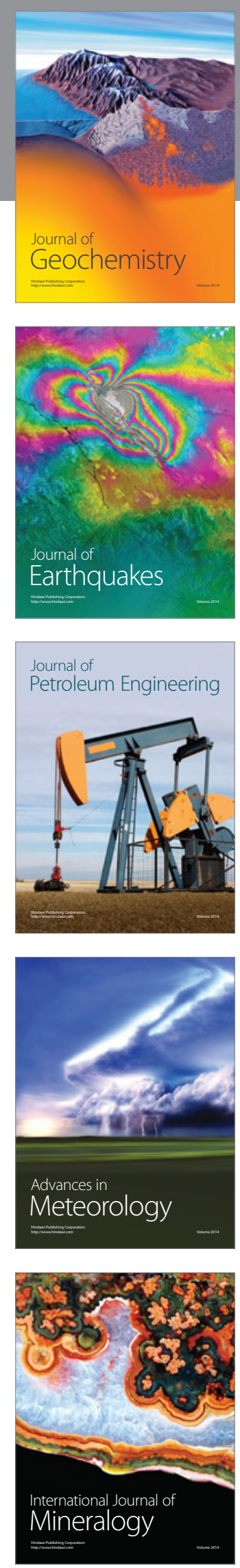
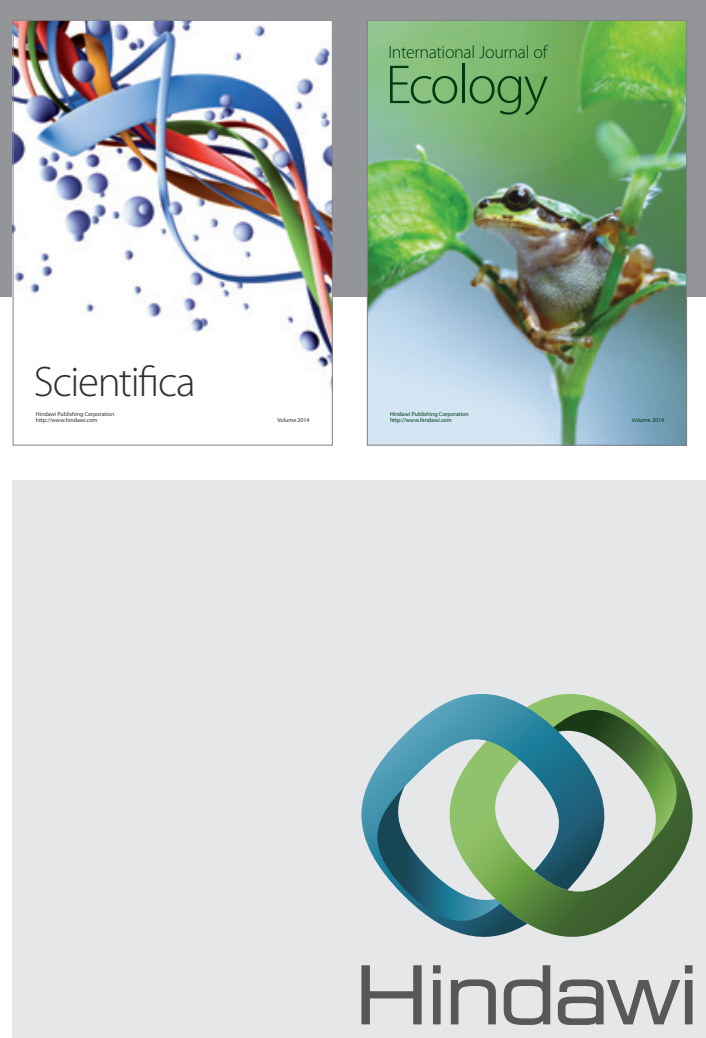

Submit your manuscripts at

http://www.hindawi.com
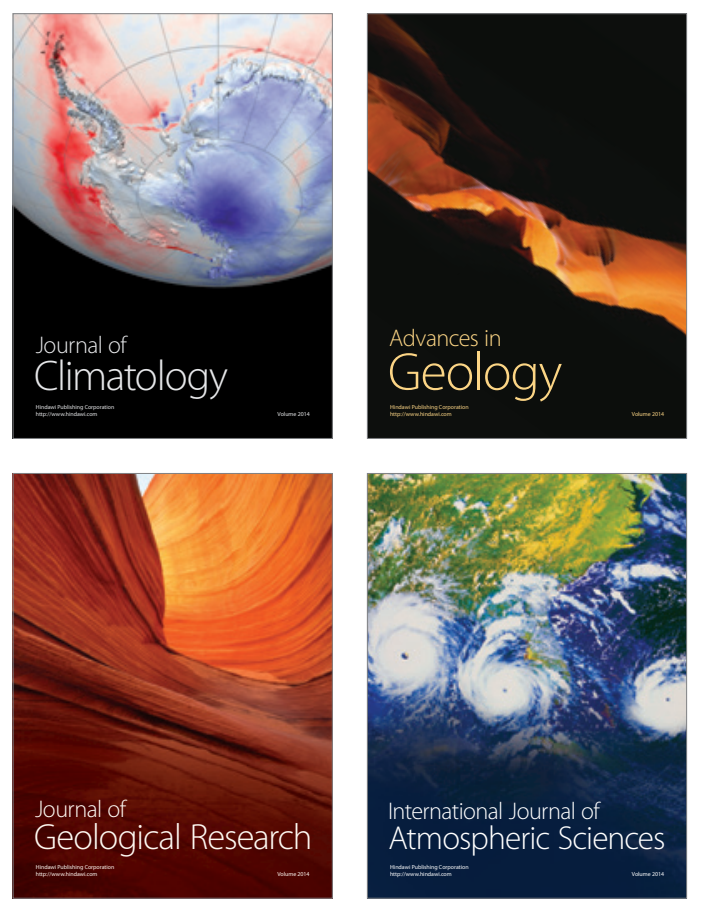

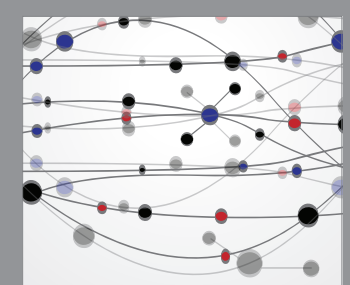

The Scientific

\section{World Journal}
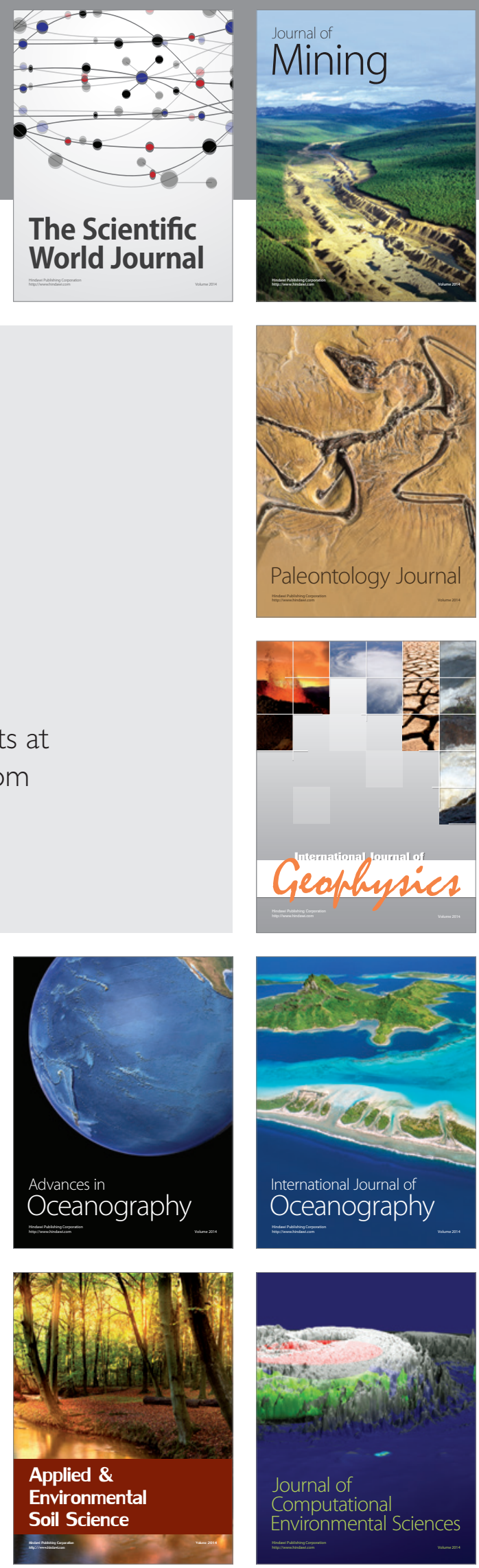